Stressors and Turning Points in High School and Dropout:

A Stress Process, Life Course Framework

\author{
Véronique Dupéré \\ Université de Montréal \\ Tama Leventhal, \\ Tufts University \\ Eric Dion \\ Université du Québec à Montréal \\ Robert Crosnoe \\ University of Texas at Austin \\ Isabelle Archambault \& Michel Janosz \\ Université de Montréal
}

\begin{abstract}
Author Note
Véronique Dupéré, École de psychoéducation and Institut de recherche en santé publique de l’Université de Montréal (IRSPUM), Université de Montréal; Tama Leventhal, Eliot-Pearson Department of Child Development, Tufts University; Eric Dion, Département d'éducation et de formation spécialisées, Université du Québec à Montréal; Robert Crosnoe, Department of Sociology, University of Texas at Austin; Isabelle Archambault \& Michel Janosz, École de psychoéducation, Université de Montréal.

Financial support for the preparation of this article was provided to V. D. by Canada's Social Sciences and Humanities Research Council (SSHRC), Fonds de recherche du Québec Santé (FRQS) and Société et culture (FRQSC) and IRSPUM.

Correspondence concerning this article should be addressed to Veronique Dupere, École de psychoéducation, Université de Montréal, C.P. 6128, succursale Centre-Ville, Montréal, QC H3C 3J7.
\end{abstract}




\begin{abstract}
High school dropout is commonly seen as the result of a long-term process of failure and disengagement. As useful as it is, this view has obscured the heterogeneity of pathways leading to dropout. Research suggests, for instance, that some students leave school not as a result of protracted difficulties but in response to situations that emerge late in their schooling careers, such as health problems or severe peer victimization. Conversely, others with a history of early difficulties persevere when their circumstances improve during high school. Thus, an adequate understanding of why and when students drop out requires a consideration of both long-term vulnerabilities and proximal disruptive events and contingencies. The goal of this review is to integrate long-term and immediate determinants of dropout by proposing a stress process, life course model of dropout. This model is also helpful for understanding how the determinants of dropout vary across socioeconomic conditions and geographical and historical contexts.
\end{abstract}

Keywords: high school dropout, precipitating factors, life course, stress process, theoretical framework, contextual influences 


\section{Stressors and Turning Points in High School and Dropout:}

\section{A Stress Process, Life Course Framework}

There have been repeated calls in the scientific literature to consider high school dropout not as an event but as a process (see Christenson \& Thurlow, 2004; Rumberger, 2011). In this view, dropout is the endpoint of a long trajectory of disengagement starting as soon as, and even before, children enter school. This long-term approach has led to breakthroughs in our understanding of the roots of dropout. Longitudinal studies spanning the first two decades of life have illuminated the role that early family circumstances and school experiences play in putting some children on a high-risk trajectory for dropout (e.g., Alexander, Entwisle, \& Kabbani, 2001; Duchesne, Vitaro, Larose, \& Tremblay, 2008; Jimerson, Egeland, Sroufe, \& Carlson, 2000; Porche, Fortuna, Lin, \& Alegria, 2011). The long-term approach also highlights the importance of starting to support highly vulnerable children early in their schooling careers, a point further supported by the relative effectiveness of early childhood education programs in reducing dropout among high-risk youth (e.g., Reynolds, Temple, Robertson, \& Mann, 2001; Schweinhart et al., 2005).

Yet, the portrayal of dropout as the logical end point of a long process of failure and disengagement may have unintentionally played down alternative routes to dropout. This situation is problematic because the population of young people who drop out of high school is highly heterogeneous and in need of differential intervention approaches (Bloom, 2010). To start with, accumulating evidence suggests that as many as $40 \%$ of dropouts do not show clear signs of disengagement or major academic or behavioral problems in the years before dropping out (Bowers \& Sprott, 2012b; Janosz, Archambault, Morizot, \& Pagani, 2008; Janosz, Le Blanc, Boulerice, \& Tremblay, 2000). Similarly, others observe that many middle school students from disadvantaged backgrounds with strong academic profiles rapidly decline after the transition to 
high school and become at high risk for drop out (Roderick, Kelley-Kemple, Johnson, \& Beechum, 2014). Understanding the causes of dropout among students who do not follow a clearly identified pathway out of school is necessary to tailor interventions to their needs (Feinstein \& Peck, 2008). Among these dropouts, precipitating factors (i.e., situations emerging for high school students not long before the decision to dropout is made) could play an important role (e.g., see Bowers \& Sprott, 2012b; America's Promise Alliance, 2014).

In addition, even among students already considered at risk when they enter high school, there is considerable heterogeneity in terms of timing and outcomes, with some leaving school later than others and others unexpectedly graduating (Bowers, Sprott, \& Taff, 2013; Vitaro, Larocque, Janosz, \& Tremblay, 2001). This heterogeneity could be determined in part by circumstances emerging late in students' schooling careers. In fact, improved circumstances in adolescence can close wide achievement gaps established during the elementary school years (Dobbie \& Fryer, 2011). Conversely, peak vulnerability could arise when early failure intersects with challenging circumstances in high school, such as when students are under important stress or are offered new opportunities incompatible with schooling (e.g., a full-time job). Attention to such precipitating factors among students following a recognizable long-term problematic path could contribute to a better understanding of when (if ever) and under what circumstances highrisk students decide to stop attending school. This understanding could help pinpoint periods of increased vulnerability during which these students are in need of heightened attention.

Some theoretical and empirical work (reviewed in the following sections) supports the premise that youth dropping out unexpectedly without having a history of learning or behavioral problems as well as youth with such a history may experience problematic life circumstances shortly before they quit. Nonetheless, in contrast to risk factors measured years before dropout occurs, proximal precipitating stressors occurring in the few months or even weeks before 
dropout occurs have received little scholarly consideration. Because of this lack of attention, non-typical dropouts are hard to identify and are thus likely to fly under the radar and receive limited support. Moreover, periods of increased vulnerability among high-risk youth may be overlooked. To better understand the role that concurrent triggering circumstances may play in the dropout process, dropout must be thought of not only as a long-term process but also as a discrete event that occurs at a particular time and place in response to specific contingencies.

More than 20 years ago, Singer and Willet (1991) discussed in this journal the advantages of treating dropout as an event that occurs as the result of both long-term processes and more immediate circumstances. In Singer and Willet's opinion, such an approach to studying dropout was rarely adopted because of the lack of adequate statistical tools at the time, a problem the two methodologists tried to fix by introducing educational researchers to event history analysis. Two decades later, few researchers have followed up on Singer and Willet's invitation to use these models to study distal and proximal predictors of dropout (exceptions include Bowers, 2010; Cho, 2011; Lamote et al., 2012; Li, 2007; Plank, DeLuca, \& Estacion, 2008; Randolph, Fraser, \& Orthner, 2006; Vitaro et al., 2001). Thus, more than adequate statistical tools are needed to move the field forward. Rather, a general theoretical formulation of dropout delineating a clear and distinct role for contemporary extraneous events, while acknowledging the crucial role of enduring risk factors, would be instrumental in this regard. In addition, a discussion of methodological issues beyond statistical modeling is warranted, notably in terms of study designs.

This article proposes one such theoretical formulation, along with a discussion of selected methodological issues. The proposed model bridges major theories of dropout with two more general models of human development that emphasize both the role of enduring risks and that of changing contextual circumstances in shaping individual trajectories: the stress process and life 
course perspectives. The stress process illuminates how individuals respond to new stressors emerging in their lives differently, depending on the nature of the stressors as well as on their personal and social resources, which are constructed over the years. The life course perspective considers how long-term trajectories are structured by turning points and transitions that deflect or reinforce life pathways. Before presenting the theoretical integration of these two models in relation to dropout, we first review the limited theoretical and empirical base suggesting a role for precipitating factors in extant dropout research.

\section{The Implicit Role of Triggering Events in Major Theories of Dropout}

Leading theorists of dropout acknowledge that quitting school is a complex phenomenon that can result from various problematic pathways. Along with risk factors that emerge early in children's schooling careers, these theorists usually discuss some of the contemporary circumstances that could precipitate dropout. However, these circumstances are often mentioned more as a side note than as a central component of dropout models. The following sections briefly review five major theories of dropout, with a focus on the role imparted to precipitating events and circumstances, over and above preexisting risks.

\section{Tinto's Sociological Theory of College Dropout}

Vincent Tinto’s $(1975,1993)$ influential model of college dropout is widely cited, including by researchers focusing on high school students. His model explicitly discusses the interplay between relatively stable risk factors for dropout present even before students enter college, such as cognitive abilities or family background characteristics, and later academic and social experiences in college. In his model, suboptimal academic progresses and inadequate social integration in college are the major factors precipitating dropout. Although focusing on college academic and social experiences, the model also touches upon events external to the school experience that can lead to dropout (e.g., new job opportunities, work pressures, or family 
problems). When challenging situations emerge within or outside the school, students may abruptly decide to quit school. For instance, problematic events unfolding over the first few weeks of college are thought to be critically important as precipitants of dropout (Tinto, 1988). In other words, if severe enough difficulties erupt in one sphere of a student's life, it may lead to a rapid decline in his or her commitment to schooling, even in the absence of prior academic problems.

Tinto’s model also points to potential interactions between various factors operating during the college years. Positive elements in the college experience are thought to have the power to mitigate the negative impact of critical challenges. For example, students who struggle academically but are integrated socially, because they participate in extracurricular activities for instance, may remain in college if they are not dismissed. Conversely, students who are isolated socially but who succeed academically are expected to pursue their education, although these students may be particularly likely to switch institutions. Thus, according to Tinto, the constellation of difficult circumstances and sources of positive supports in school and outside of school need to be considered holistically to make sense of students' decisions to drop out or stay in college.

In short, Tinto's model is consistent with the premise that problematic situations emerging very late in students schooling careers can precipitate dropout. However, not all potentially relevant situations are included in his model. For instance, critics point to a lack of attention to structural constrains extending beyond school and outside of students’ control, such as insufficient access to financial aid or cultural capital, that may place students in difficult situations that impair their academic and social integration and, ultimately, their schooling success (for a review, see Metz, 2004; see also Tinto, 1982). In any case, even the stressful situations that were explicitly discussed by Tinto as potential precipitants have not been widely 
modeled as such in empirical studies of high school dropout, perhaps because the model focuses on college dropout and thus does not specify which situations are the most likely to act as precipitants of high school dropout.

\section{Wehlage's Theory of High School Dropout Prevention via School-Based Reform}

Another well-known model is that of Gary G. Wehlage and colleagues (Wehlage, Rutter, Smith, Lesko, \& Fernandez, 1989), which explicitly focuses on dropout among high school students. Drawing on Tinto’s model and findings from a mixed-method study conducted in schools considered successful at retaining students, Wehlage focuses on identifying school-level factors associated with student retention over which practitioners and policy makers have some control, such as pedagogical approaches or school climate. In line with this focus, Wehlage's model is widely used as a theoretical foundation for studies examining associations between school dynamics and dropout (see Rumberger, 2011).

Although focusing on school-level dynamics affecting dropout decisions, Wehlage also discusses the heterogeneity of the dropout population. To illustrate, he describes cases that do not fit the dropout stereotype, such as relatively high-achieving, middle-class students who drop out after bouts of severe victimization due to their physical appearance; social isolation following a residential move; physical or mental health problems; the birth of a child; or family problems, including parental separation, disease, or even death. For Wehlage, preventive efforts that do not take this range of diversity into account miss an important part of the picture and are doomed to limited success (see also Bloom, 2010; Bloom, Thompson, \& Ivry, 2010; Janosz et al., 2000). In contrast with the parts of the model focusing on school-level dynamics, Wehlage's discussion of the triggering role of life events has received much less research attention. 


\section{Finn's Developmental Theory of High School Dropout}

Another influential model of high school dropout is that of Jeremy D. Finn (1989). This model explicitly adopts a developmental perspective on dropout. Finn’s model highlights two long-term pathways that can lead to dropout and that are set in motion as soon as children enter the school system. In the first one, called the frustration-self-esteem pathway, early school failure leads to the internalization of a negative self-concept and then fuels frustration and rebellion in a cycle that ultimately results in further failure and dropout or dismissal. Finn also describes a second participation-identification pathway that does not necessarily start with early learning problems. Rather, it is launched when children enter school ill equipped to participate in classroom activities because of a lack of support and preparation at home. Because participation is suboptimal (for instance because of irregular attendance), the child does not develop a sense of belonging in school, which further decreases participation. This negative feedback loop is thought to lead to lower engagement and achievement in school and ultimately result in dropout. The two pathways described by Finn are reminiscent of Tinto's concepts of academic and social integration, although they are applied much earlier in students’ schooling career.

In line with other developmental models of problematic outcomes in adolescence (e.g., Cicchetti \& Rogosch, 2002), Finn notes that such long-term pathways of self-reinforcing transactional processes are not the only ones leading to dropout and that some individuals are up to a good start but "encounter incidents along the way that cause them to withdraw" (p. 131), such as new obligations to work or to take care of family members. However, Finn does not explicitly integrate such precipitating factors in his model or otherwise elaborate on their importance. Like Tinto and Wehlage, Finn recognizes that proximal events may be of consequence for some students, but he concentrates on the processes unfolding in the long term. 


\section{Dropout as Part of a General Deviance Construct: Moffit's Developmental Taxonomy of}

\section{Antisocial Behaviors}

Although not focusing exclusively on dropout, other developmental models found in the general literature about risk-taking and delinquency are relevant. Dropout is often conceptualized as a deviant behavior that shares common developmental roots with other behaviors, such as delinquency and drug use (e.g., Battin-Pearson et al., 2000; Jessor, 1998; McGee \& Newcomb, 1992). If dropout is part of a general deviance construct and shares etiological roots with delinquent behaviors, then it too could follow one of the two pathways to delinquency described in Terry E. Moffit’s $(1993,2008)$ influential developmental taxonomy of antisocial behaviors. In one of the pathways suggested by Moffit, antisocial behaviors start early in children's lives and result mostly from the accumulated consequences of individual risk factors. By contrast, in the second pathway, antisocial behaviors result from the emergence, during the latter half of adolescence, of new circumstances that temporarily heighten the rewards associated with antisocial behaviors.

The first pathway (that of life course persistent antisocial behaviors) is characterized by a profile of enduring problematic behaviors that start early and perpetuate well into adulthood. Among the group of early-starters following this pathway, antisocial behaviors are thought to arise in large part from neuropsychological deficits, as expressed by poor impulse control and suboptimal learning. In turn, children's antisocial behaviors tend to elicit negative reactions from both parents and teachers, perhaps especially in disadvantaged contexts where adults have less resources to deal with unruly children. These reactions are believed to exacerbate the effects of early neuropsychological deficits. As a result of this negative feedback loop, children become entrenched in deviant lifestyles, with diminishing opportunities for reorientation towards more conventional pathways. The description of this pathway closely matches Finn's view of dropout 
as the end point of a long, self-reinforcing process of academic failure and disengagement that is set in motion immediately following school entry.

The second pathway (that of adolescence-limited antisocial behaviors) is much more prevalent, if less severe. It is characterized by a short-lived experimentation with delinquency and risk taking that usually starts between 15 and 17 years old, and that rapidly recedes in young adulthood. Typically, youth following this pathway do not engage in antisocial behaviors as intensely or consistently as their life course persistent counterparts, but they may still experiment with a variety of these behaviors, including shoplifting, truancy, substance use and trade, and risky sexual and driving behaviors, for instance. This second pathway is not associated with a history of particularly low achievement or problematic social skills. Rather, antisocial behaviors arise only later, as reactions to new circumstances emerging in high school.

These new circumstances are brought about by both biological and social processes. At the time when adolescents enter high school, their social-emotional brain system is maturing more quickly than their cognitive-control system, placing them at risk for reckless behaviors (Steinberg, 2008). They also strive for autonomy in a context that provides few opportunities to experiment with adult roles and responsibilities. In this context, antisocial behaviors are temporarily used by some previously well-adjusted adolescents to affirm their independence and gain status among their peers. When these contingencies dissipate in late adolescence and early adulthood, youth following the second pathway gradually cease to exhibit antisocial behaviors. Thus, the second pathway usually entails no enduring consequences. There are, however, exceptions. For instance, experimentation with risky behaviors can lead to early pregnancy, conviction, addiction, or major car crashes, situations with very real long-term consequences that can interfere with schooling and lead to dropout. As such, the adolescent-limited pathway is consistent with the premise that changing circumstances may drive previously well-adjusted 
adolescents to dropout. Interestingly, findings from typological studies show that a significant proportion of dropout students experience an unexpected and abrupt academic decline in late adolescence (for a review, see Bowers \& Sprott, 2012b; see also Roderick et al., 2014).

\section{Rumberger's Synthesis of Risk Factors Shaping Students’ Perseverance in High School}

In a model distilling insights from the major theories and empirical literature on dropout and related deviant behaviors, Russell W. Rumberger (2011) classifies the antecedents of dropout in two broad categories: individual and institutional. Individual antecedents include students’ background characteristics (demographics, health and prior academic performance and experiences), attitudes (goals, values, self-perceptions), and behaviors (engagement, coursework, deviance, peers, employment). Institutional antecedents include the structure and processes operating within families, schools, and communities. His model also stresses the interplay between individual and institutional factors, with institutional factors shaping the associations between individual risks and dropout. Rumberger's model can be seen as an application of bioecological models of human development (Bronfenbrenner \& Morris, 2006; Shonkoff et al., 2012; Steinberg \& Morris, 2001) to high school dropout, with lower and higher order contexts interacting with one another to produce developmental outcomes.

An important contribution of Rumberger's model is its emphasis on the diverse nature and multilevel structure of risk factors for dropout. However, by making no reference to developmental period or chronological age, this dropout model, like its predecessors, does not single out the distinct role of proximal life events and circumstances. This may be because it is based on an empirical dropout literature that largely does not consider the interplay of long-term risk factors and precipitating events. This gap in the extant empirical base reflects some methodological issues (as discussed next) as well as the lack of a comprehensive dropout theory articulating the role of both long-term and more immediate risk factors. 


\section{Empirical Studies Linking Proximal Events and Dropout:}

\section{A Critical Review from a Methodological Perspective}

The examination of the interplay of long-term risk factors and contemporary precipitating circumstances is bounded by significant methodological limitations of the two leading designs used in dropout research. On the one hand, longitudinal prospective studies, the gold standard for uncovering long-term patterns of risks, often are not well suited for identifying contemporary precipitating factors for reasons explained below. On the other hand, retrospective studies focusing on the circumstances just preceding dropout (e.g., within a year prior to dropout) have not adequately addressed the issue of pre-existing, long-term vulnerabilities. Interestingly, despite these methodological limitations, disparate empirical findings support the premise that, in addition to the well-known long-term risks, immediate circumstances in adolescence play a precipitating role in high school dropout.

\section{Prospective Longitudinal Studies of General Adolescent Development}

Longitudinal prospective studies starting in early childhood and following participants until the end of adolescence are typically of limited usefulness for examining high school precipitants of dropout for a number of reasons. To begin with, at-risk families often do not enroll in these studies, and when they do, they are frequently lost to follow-up long before the targeted children reach adolescence (e.g., Wolke et al., 2009). To illustrate, a systematic review of longitudinal studies starting in early childhood found that the average rate of attrition exceeded $30 \%$ by the time participants reached their fifteenth birthday and was almost at $40 \%$ for special populations of the same age (Weinfield, Bollmer, Krueger, \& Eaker, 2011). Administrative data about dropout and graduation can be obtained for those lost to follow-up, allowing researchers to link early risks with later attainment despite attrition. However, for lost cases (among which 
dropouts are sure to be overrepresented), no information will be available about their life circumstances during the high school years.

Even in longitudinal studies with high retention rates, other coverage problems exist. An important one stems from the ubiquitous use of infrequent assessments during the adolescent years. A common practice is to separate assessments by periods of 12 or 24 months, or more. For instance, in the National Longitudinal Study of Adolescent Health, a major study of adolescent development, assessments were separated by at least 12 months and up to 5 years (Harris, 2012). As such, a participant who drops out will, in all likelihood, be interviewed months or years after having done so, precluding a full examination of the circumstances surrounding the decision to drop out. It is not surprising then that longitudinal studies have been most useful for uncovering predictors of dropout measured years before dropout occurs but less useful for identifying factors precipitating dropout, with some interesting exceptions reviewed next.

Direct links between proximal events and dropout. Regardless of the often long intervals between assessments, participants can be asked about events that happened between waves of data collection. To avoid overburdening participants, existing studies typically ask only about a limited range of between-wave events that can be easily dated, such as residential or school changes, parental imprisonment, or the birth of a child. As incomplete as it is, analyses of these sorts of data suggest that proximal events are relevant. For instance, a study based on the National Longitudinal Survey of Youth found that students who had switched schools during the high school years were at an increased risk for dropout, as compared with a carefully matched group who had not (Gasper, De Luca, \& Estacion, 2012; see also Worrell, 1997). Data from similar surveys were used to document links between dropout or related outcomes and major changes brought about by teen parenting (e.g., Ashcraft, Fernández-Val, \& Lang, 2013; Fletcher 
\& Wolfe, 2009), grade retention (see Jimerson \& Brown, 2013), family instability (e.g., Cavanagh \& Fomby, 2012; Fomby \& Bosick, 2013), parental imprisonment (Hagan \& Foster, 2012), physical and mental health problems (e.g., Breslau, 2010; Homlong, Rosvold, \& Haavet, 2013), and long working hours (e.g., Lee \& Staff, 2007; Monahan, Lee, \& Steinberg, 2011).

To widen the set of proximal events that could be linked to dropout, other researchers have turned to administrative data sources. For instance, Kirk and Sampson (2013) appended data on arrests from police records to longitudinal survey data from the Project on Human Development in Chicago Neighborhoods. Their results showed that an arrest during the high school years heightened the probability of dropping out, controlling for other factors (see also Hirschfield, 2009). Administrative data also were used to demonstrate an association between dropping out and hospitalization (van Heesch, Bosma, Traag, \& Otten, 2012), foster care placement (Vinnerljung, Öman, \& Gunnarson, 2005), parental imprisonment (Cho, 2011), as well as changes in family income and maternal employment (Randolph et al., 2006).

The self-reported and administrative data collected in the context of longitudinal studies illustrate the importance of considering proximal events emerging in high school not long before dropout occurs. However, the information is limited to events that can be reliably dated retrospectively in surveys or archived in administrative records. Because of data limitations, other potentially important, but more diffuse, events (e.g., flare up of a conflict with a teacher at school) have not been considered. In addition, because these studies largely examine the role of a single type of event (e.g., teenage pregnancy), their findings provide an incomplete and fragmented picture of the precipitating circumstances leading to dropout.

Potential moderators. In general, the studies reviewed find that various unfavorable life events and circumstances emerging during high school are independently associated with dropout over and above pre-existing vulnerabilities, thus underscoring the relevance of proximal events in 
the dropout process. Existing research also suggests that the impact of these events is moderated by their nature and perhaps the context in which they occur. To begin with, the strength of the association between proximal events and dropout is variable across studies, ranging from small to moderate. In general, relatively rare events that would be regarded as highly stressful in almost any context, such as youth arrest and parental incarceration (Cho, 2011; Hirschfield, 2009; Kirk \& Sampson, 2013), tend to have stronger associations with dropout than more commonly occurring events with a severity that is conditional on context, for instance school mobility or family disruptions (Cavanagh, Schiller, \& Riegle-Crumb, 2006; Gasper et al., 2012). Because studies typically focus on only one type of event at a time, the possibility that events of a distinct nature are differentially associated with dropout generally remains unexamined.

A small number of studies have considered the moderating influence of event severity or students’ prior vulnerability. In terms of event severity, van Heesch et al. (2012) found that the association between hospitalization during high school and dropout was especially strong for repeated or prolonged hospitalization. In addition, hospitalization predicted dropout among student in a pre-university tract but not among their usually more at-risk peers in vocational programs. Similar results were found for long working hours and school mobility, two events that were associated with dropout only among those who were not particularly at risk of experiencing these situations (Gasper et al., 2012; Lee \& Staff, 2007). In line with Moffit’s (1993) observations, it may be that circumstances emerging in high school are especially relevant for youth who were not previously on a highly problematic track. For youth who were on such a track, precipitating events may be more relevant for understanding the timing of dropout, rather than its occurrence per se.

In sum, existing research suggests that it is necessary to take into account the circumstances in which an event occurs, both in terms of the contemporary presence of other 
stressors or resources and previous experiences and outcomes. The scarcity of moderation studies reflects the lack of a comprehensive theoretical discussion of precipitating factors in relation to other risks, as well as the data limitations outlined. Notably, a complete picture of the events experienced before dropout is required to answer questions about the accumulation and configuration of different types of events. Studies specifically focusing on the circumstances surrounding dropout are apt to provide a more complete picture of precipitating factors. However, such studies have limitations, as described next.

\section{Retrospective Studies in which Dropouts are Asked about Precipitating Factors}

One obvious way to gather information about the circumstances and events just preceding the decision to dropout is to directly ask dropout students about it. Studies adopting this approach specifically focus on dropout rather than generally assess adolescent development. Accordingly, these studies have room to cover a wide range of potential precipitating factors surrounding the decision to leave school. Two types of studies have relied on this approach.

First, relatively large questionnaire-based surveys have been conducted among samples of dropouts (e.g., Berktold, Geis, \& Kaufman, 1998; Bridgeland, DiIulio, \& Morison, 2006; Dalton, Glennie, \& Ingels, 2009). Findings from one influential survey based on a diverse sample of dropouts are largely consistent with the premise that dropouts are a heterogeneous group and that they may leave school for many reasons beyond academics (Bridgeland et al., 2006; see also America's Promise Alliance, 2014). For instance, a majority of dropouts reported that they had passing grades and that they had left school two years or less before they would have met graduation requirements. Although school- and academic-related reasons were most frequently cited as reasons for dropping out, many students also explained their decision by invoking an outside event, such as getting a job, becoming a parent, or needing to support family members. Similar results are reported in nationally representative surveys (e.g., Dalton et al., 2009). 
Second, to cover in more depth an even wider range of potentially precipitating events, other researchers have opted for semi-structured individual interviews and qualitative analytical approaches (e.g., Beekhoven, 2005; Clandinin, Steeves, \& Caine, 2013; Ferguson, Tilleczek, Boydell, \& Rummens, 2005; Lessard et al., 2008; Wehlage et al., 1989). These studies also allow for both a qualification of the wider context in which potentially precipitating events take place and a fine-grained understanding of the timing and sequencing of these events. The resulting narratives show that dropout often occurs in the footsteps of a wide range of events, such as prolonged hospitalization, car accidents, pregnancies, conflicts at school with a teacher or a peer, recent immigration problems, being kicked off a school sports team, pressures to work more, peer rejection and bullying, parental incarceration, death, separations, or new relationships. Such pivotal events might be present in almost $50 \%$ of cases (Lessard et al., 2008). Interviews also suggest that youth who drop out are often dealing with many difficult circumstances simultaneously (see also America's Promise Alliance, 2014). Because the accumulation of unfavorable events could be especially problematic, researchers need to consider the configurations of these circumstances rather than viewing them as isolated events.

The richness of the accounts provided by survey- and, especially, interview-based studies of dropouts comes at the cost of significant methodological limitations. Importantly, these studies do not easily allow for a balanced examination of the relative role of early vulnerabilities and proximal triggering events. Dropouts' conscious narratives are likely to stress factors more immediately and obviously related to their decision to drop out and not those that operate more subtly over the course of many years, as noted by Rumberger (2011). Another major limitation of these studies is the absence of credible comparison groups of students who do not drop out but are otherwise similar to students who do. The lack of a basis for comparison means that it is difficult to discern the events described by dropouts that are important from those that are not. 
For instance, many dropouts may report experiencing a family transition not long before dropping out but such transitions may be just as common among similar students who remain in school. Without an appropriate comparison group, these issues cannot be sorted out.

The studies just reviewed suggest that dropout could be precipitated by a wide range of events, including (but not limited to) school mobility, teen parenting, juvenile arrest, and health problems. A complete picture of the role of these events cannot be drawn, however, because of methodological limitations of the available research. On the one hand, longitudinal studies offer only a partial, decontextualized, and fragmented portrait of the circumstances surrounding the decision to drop out. On the other hand, studies in which dropout students are interviewed in depth about the circumstances surrounding their decision to quit school lack credible comparison groups, making it impossible to tease out which, among numerous reported events, may influence the decision to drop out over and above pre-existing risks. More generally, there seems to be a schism between dropout researchers, who understand dropout largely in terms of the past (i.e., long-term risks) and dropouts themselves, whose own explanations focus on the present (i.e., recent precipitating events). To bridge this gap and better address the interplay of early risk factors and proximal precipitants in dropout research, both theoretical and methodological developments are needed.

\section{Dropout in a Stress Process, Life Course Perspective}

Both stress process and life course models extensively discuss questions related to changes and inflections in individual developmental trajectories following disruptive events and major life changes, while also taking into account individuals’ developmental histories and life

contexts. However, they approach these questions from different angles. Stress process models take a rather focused lens to examine how specific combinations of individual and social vulnerabilities, stressors, and supports come together to create particular health-related outcomes 
(often among individuals from different socioeconomic backgrounds) in studies usually spanning bounded periods of a person's life. Life course models take a wider lens to examine how whole lives unfold against particular backdrops defined by historical time and geographical place. Life course models address both long-term antecedents of important life transitions, as well as their enduring consequences, in broad developmental terms not limited to health. In some ways, the stress process model allows life course researchers to zoom in and detail how global life course patterns translate into more immediate exposure and access to various stressors and resources. Conversely, the life course model allows stress process researchers to zoom out and consider the wider historical, geographical, and developmental context in which stress processes are embedded.

Despite their complementarities, the stress process and life course models evolved on separate tracts (Turner \& Schieman, 2008) until leading theorists from both perspectives recognized the advantages of bridging these two approaches (Elder, George, \& Shanahan, 1996; Elder \& Giele, 2009; Pearlin, 2010). As a result of efforts towards integration, empirical studies incorporating both perspectives emerged in recent years (e.g., Wickrama, O'Neal, \& Lorenz, 2013). Typically, these studies focus on health outcomes among older adults (Avison, 2010; Pearlin, 2010; Turner \& Schieman, 2008). Integrative stress process, life course models thus remain to be extended and applied to outcomes in other domains and in other developmental periods (Pearlin, 2010). The next sections propose such an integrative model, as applied to high school dropout and the transition from adolescence to early adulthood. Before introducing the full model, descriptions of major concepts from both the stress process and life course perspectives are presented and linked to concepts and findings from the dropout literature. The more specific stress process perspective is presented first, then the angle is widened to include macro life course concepts. 


\section{The Stress Process as a New Angle to Look at Dropout}

So far, the stress process framework has been applied primarily to study depression and other mental health problems (Pearlin \& Bierman, 2013). However, the scope of the model extends beyond mental health, and many factors underscore its relevance for educational attainment. High school dropout is not a mental illness, but it too can be thought of as a retreat in the face of stressful or defeating social situations, in a manner analogous to depression or, to take an extreme case, suicide (see Quiroga, Janosz, Bisset, \& Morin, 2013; Taylor, Gooding, Wood, \& Tarrier, 2011). Although analogies between dropout and mental illness and suicide should be used with caution (Tierney, 1999), it is interesting to note that Tinto's now classic model of student dropout drew heavily on Durkheim's theory of suicide, as Tinto viewed both as forms of voluntary withdrawal from one’s community (Tinto, 1993). Perhaps more importantly, the relevance of the stress process model in education is also supported by studies showing that psychosocial stress influences learning and cognition (e.g., Blair \& Raver, 2012; Evans \& Schamberg, 2009; Quesada, Wiemers, Schoofs, \& Wolf, 2012). Moreover, recent findings suggest that stress reactivity is particularly high during adolescence (Romeo, 2013; van den Bos, de Rooij, Miers, Bokhorst, \& Westenberg, 2014), thereby highlighting the potential importance of acute stress in the dropout process. Further links between major concepts of the stress process and dropout are proposed in the next sections.

Stressors: distribution, proliferation, and configuration. At the center of the stress process framework is the concept of stressors, broadly defined as problematic external circumstances and experiences apt to challenge people's adaptive capabilities and to precipitate the onset of adjustment problems (Pearlin \& Bierman, 2013). Stressors can take either the form of disruptive discrete events (e.g., a car accident) or relatively prolonged hardships and difficulties (e.g., physical disability following a car accident). The stress process model details 
how, and under what circumstances, such stressors are associated with the emergence of adjustment problems. It also documents the unequal distribution of stressors and resources among various socioeconomic groups, with people in disadvantaged groups often being particularly vulnerable to certain kinds of stressors, such as income loss or job and family instability.

Researchers in the stress process tradition have long observed that the relationship between stressors and individual adjustment is largely indirect (Pearlin, 2010; Pearlin \& Bierman, 2013). A particular stressor usually has an impact on adjustment through other secondary stressors that stem from it. A classic example is involuntary job loss being related to depression via the financial difficulties and family tensions it often unleashes. The concept of stress proliferation explains the observation that stressors tend to come in bundles, creating cumulative adversity. Analogous concepts developed in the child development literature, convey the notion that the accumulation of stressors is particularly problematic (e.g., Evans \& Cassells, 2014; Evans \& Schamberg, 2009). For instance, toxic stress, as opposed to positive or tolerable stress, is described as a dysregulated stress response triggered by chronic exposure to multiple severe stressors such as parental substance abuse and neglect, without access to adequate adult support (Shonkoff et al., 2012). Concepts such as proliferation and toxic stress discourage a narrow focus on a single stressor. Rather, researchers working within the stress process framework are encouraged to consider the full configuration of stressors to which an individual is exposed over time.

In studies of dropout, stress proliferation and configuration suggests, for instance, that parental divorce may be especially likely to curb school perseverance when it comes with other stressors, such as a significant loss of family income, parental substance abuse, residential mobility, and social isolation upon entering a new school (Amato, 2010). In the same manner, 
maternal incarceration could be especially problematic when it means a loss of legal custody, economic hardship, residential instability, and stigmatization (Cho, 2011; Murray \& Farrington, 2008). To offer a final example, the negative impact of adolescent arrest on schooling outcomes is probably exacerbated when it leads to a period of confinement in a juvenile detention facility (Kirk \& Sampson, 2013). All of these adverse situations could be further compounded among students experiencing structural stressors brought about by racism or poverty. For instance, stigmatized groups underperform when exposed to stereotype threat, because their fear of confirming negative stereotypes acts as an acute stressor that drains cognitive resources and undermines performance (Schmader, Johns, \& Forbes, 2008; Steele, 1997). Empirically, there are indications that an accumulation of severe stressors is especially problematic for adolescent adjustment (Flouri \& Kallis, 2007; Kirk \& Sampson, 2013). Thus, a dropout model explicitly incorporating precipitating factors should consider the whole range of stressors to which adolescents are exposed.

Moreover, the focus of the stress process on the unequal distribution and configuration of stressors across socioeconomic lines is also relevant for dropout studies. It could contribute to a better understanding of the mechanisms linking socioeconomic conditions, such as poverty, and high school dropout, which currently remain unclear (Alexander et al., 2001; Rumberger, 2011). One explanation for the association between poverty and dropout from a stress process perspective is that adolescents from disadvantaged backgrounds may be exposed to a greater variety of stressors (i.e., stress proliferation) than their more advantaged peers (Pearlin \& Bierman, 2013; as applied to childhood, see Evans \& Cassells, 2014). In other words, the skewed distribution of stressors, structured along socioeconomic lines, has potentially important consequences for young people's life chances, not only in terms of health (the typical focus of stress process research) but also in terms of educational attainment. 
Factors moderating the impact of stressors: resources and vulnerabilities. The stress

process framework also highlights many ways in which individual and social resources moderate the impact of stressors on individual adjustment (see also Shonkoff et al., 2012). On the positive side, access to resources may diminish the likelihood that an environmental stressor will generate significant strains and, ultimately, major adjustment problems. Protective influences may come from internal resources (e.g., coping repertoires, mastery, self-esteem, core values) as well as external social or institutional resources (e.g., social and instrumental supports). These concepts are akin to the protective role in dropout models attributed to factors such as social and academic integration within the school or to institutional practices and resources that are thought to support student perseverance (Tinto, 1975, 1993; Wehlage et al., 1989).

On the negative side, related vulnerability-stress models of psychopathology propose that young people's reactions to stressors depend on a complex interplay between recent stressors and pre-existing biological (e.g., genetic or epigenetic risks), psychological (e.g., cognitive ability, personality, temperament, self-regulation), or social (e.g., child abuse, prolonged poverty) vulnerabilities (Belsky \& Pluess, 2009; Hankin, 2012; Hankin \& Abela, 2005). These models notably focus on the joint contribution of distal vulnerabilities and proximal stressors in the onset of discrete problematic outcomes that occur at a particular time (e.g., onset of a major depressive episode), not unlike dropout.

Many forms of vulnerability-stress models have been proposed (Ingram \& Luxton, 2005). Some are based on an additive view, where the total amount of vulnerability and stress must attain a certain threshold for individuals to manifest a given problematic outcome. According to this view, the threshold can be attained both by a combination of high long-term vulnerability and minor contemporary stress (following the kind of processes described by Finn, 1989) or low vulnerability and severe contemporary stress (following the kind of processes thought to be 
relevant for unexpected dropouts, described by Bowers \& Sprott, 2012b). Other models are interactive and posit, for instance, that a certain degree of intensity must be attained in both vulnerability and stress for problematic outcomes to emerge.

Yet other models propose a dynamic view of individual vulnerabilities as changing over time in response to people's developmental history and past exposure to severe stressors. For instance, adolescents may become more sensitive to stress after having experienced child abuse or previous episodes of mental illness (Monroe \& Harkness, 2005; Morris, Ciesla, \& Garber, 2010; Stroud, Davila, \& Moyer, 2008). The relationships between vulnerability and stress are further complicated by the observation that past stressors may increase not only sensitivity to future stress, but also exposure to it, in a process of stress generation (Hammen, 2006; Liu \& Alloy, 2010). For instance, exposure to severe stressors such as child abuse increase the risk for depression, which in turn strains interpersonal relationships and performance, resulting in an increased likelihood of future life events involving conflicts, break-ups, or dismissals. Because of these processes, a range of individual past experiences and characteristics that are associated with stress generation in the behavioral, social, psychological, or emotional spheres must be taken into account when examining the precipitating role of stressors in relation to the onset of problematic outcomes.

Finally, recent reappraisals of vulnerability-stress models posit that some individuals may simply be more sensitive to all features of their environment, whether negative or positive (Belsky \& Pluess, 2009). Such differential susceptibility models suggest that individual vulnerabilities might interact not only with stressors but also with sources of environmental support.

To sum up, a model of dropout adopting a stress process perspective would need to consider a wide range of stressors to which youth might be exposed in high school as well as the 
unequal distribution of these stressors across socioeconomic lines. It also would have to take into account protective factors that could blunt the impact of new stressors emerging in high school as well a wide range of pre-existing internal and external vulnerabilities and strengths building up before high school. Relations between these pre-existing factors and proximal stressors would need to be considered both in additive, interactive, and dynamic terms. Moreover, theorists of the stress process have encouraged researchers to situate their inquiries within the larger life course model (Pearlin, 2010), presented next.

\section{The Life Course Perspective and Dropout: Extending Existing Links}

In contrast with the stress process framework that remains untapped in the dropout literature, insights from the life course perspective have already contributed to enhancing our understanding of dropout (e.g., Alexander et al., 2001). However, only some of the central concepts of the life course perspective have been used, leaving room for further developments. Importantly, existing investigations of dropout from a life course perspective have not integrated the wider contextual elements of the life course paradigm, echoing a general tendency in dropout and engagement literature to focus on individuals, families, and schools but not on wider contextual influences (Lawson \& Lawson, 2013). In the following sections, lower-order life course concepts that are already well integrated in the dropout literature are briefly discussed. Then, higher-order ones typically not considered in dropout research about larger contextual influences beyond the school are discussed at greater length. These concepts are presented in relation to high school dropout, while highlighting affinities with relevant concepts from the stress process model.

Long-term developmental pathways. The core concept of long-term developmental pathways underlies life course theory (Elder, 1998; George, 2013). As applied to adolescence, it means that outcomes such as dropout can be fully understood only in light of previous childhood 
experiences and outcomes (Kirkpatrick Johnson, Crosnoe, \& Elder, 2011). In the dropout literature, some researchers using longitudinal data spanning both childhood and adolescence have couched their work within a life course framework and looked for antecedents of dropout during the elementary and middle school years. Studies adopting such a long view are consistent with the consideration of pre-existing vulnerabilities within the stress process framework.

One well-known example of a dropout study that explicitly adopted a life course perspective is that of Alexander et al. (2001). In addition to the life course perspective, their work is based on Finn's (1989) developmental model of dropout, which underscores the role of early school experiences in putting some children at risk. Alexander et al.'s (2001) results uncovered many links between early individual, school, and family experiences and dropout. They also highlighted that over and above early experiences, some risk factors measured at later stages (up until ninth grade) remained significantly associated with dropout. However, new events and situations emerging beyond middle school were not considered in this study. Other longitudinal studies of dropout starting in the primary grades report similar results, underscoring continuity of risk over the course of children’s schooling careers (e.g., Barry \& Reschly, 2012; Duchesne et al., 2008; Entwisle, Alexander, \& Olson, 2005; Jimerson et al., 2000; Reynolds, Ou, \& Topitzes, 2004).

Turning points. The life course framework stresses not only continuity with previous development but also the importance of points of rupture and discontinuity in individual trajectories (Crosnoe \& Johnson, 2011; Kirkpatrick Johnson et al., 2011). Turning point is the life course term used to refer to a significant departure from past development (Cohen, 2008; Elder, 1986; Rutter, 1996). A turning point is likely to be brought about by major life events that are powerful enough to reshape and redirect people’s lives. There is a significant overlap between the concept of turning point and that of stressors in the stress process model. However, 
turning point represents a broader concept than stressors because the former also refers to positive transitions and experiences (Rutter, 1996). For instance, in the field of criminology, the concept of turning point is used to understand life changes that encourage desistance from criminal lifestyles, such as employment, marriage, or military service (e.g., Kirk, 2009; Laub \& Sampson, 2003). As reviewed previously, the proximal events studied as potential turning points in relation to high school dropout, such as hospitalization and arrest, mostly have been on the negative side - that is, consistent with the stress process notion of stressors. Yet, events and transitions allowing for fresh starts and new ways to feel valued and engaged in one's education also could contribute to upward shifts in problematic educational trajectories, a proposition that has received scant attention (see Yair, 2009). However, events considered as positive from the point of view of an adolescent could still be associated with earlier termination of schooling, such as engagement in a new job (Lee \& Staff, 2007).

Timing. The impact of turning points is thought to be dependent on their timing in relation to developmental milestones (Elder \& Giele, 2009). For instance, Elder (1999) showed that the developmental consequences of major family income losses during the Great Depression of the 1930s differentially affected youth who were children at the time of the crisis as compared with those who were well into their teens and could rely on their own coping resources. For adolescents, but not for children, the crisis provided growth opportunities. Thus, developmental timing can significantly change the meaning of a given stressor, as it determines, in part, the nature and strength of individuals' goals and internal coping resources. The concept of timing thus underscores the importance of separately considering the educational impact of stressors occurring in the late high school years, as this is a critical developmental junction when adolescents are finishing high school and preparing to go out into the world as young adults. 
Linked lives. The life course concept of linked lives conveys that adolescents’ lives are shaped by the lives of significant others around them, including parents, peers, schoolmates, and teachers. This notion is supported by a vast literature linking family, friend, or school characteristics to dropout (for a recent review, see Rumberger, 2011). It also clearly applies to many identified precipitants of dropout involving other people, such as parental incarceration or family instability. From a stress process perspective, these significant others are relevant not only as a potential source of stress but also as a major source of support in adolescents' lives. When a significant other is under stress, the pressure may translate to adolescents through diminished support, because parents undergoing a financial crisis are less available to support adolescents, for instance (Conger, Conger, \& Martin, 2010).

Agency. In addition to timing, the life course concept of individual agency is also related to the stress process notion of coping resources. Agency refers to people's ability to make choices and deliberately adapt to their life circumstances as a function of their contemporaneous goals and resources. Life course models also consider how agency is expressed within boundaries that can be more or less constrained depending on context. For instance, individual agency regarding school perseverance and dropout may be limited when parents and other significant adults in the community consistently and forcefully support graduation. Conversely, in families and schools where norms are less consistent and where both dropout and graduation are common, gaps in terms of individual agency and resilience are likely to be more vividly expressed (Harding, 2011). To a large extent, constraints placed on adolescents’ agency are structured by significant others as well as by important local and historical contingencies.

Geographical and historical contexts. Beyond the role of socio-economic position already incorporated in the stress process framework, the life course perspective offers other important insights about macro processes that may shape dropout decisions. Notably, it proposes 
that lives are embedded in specific geographical and historical contexts, and that these contexts reverberate on development. In contrast with other important tenets of the life course perspective that are well researched in the dropout literature (even if not always explicitly couched in life course terms), broad geographical and historical phenomena often are overlooked in this literature (see Lawson \& Lawson, 2013). To rectify this situation and encourage dropout researchers to pay more attention to broad contextual influences, literature focusing on geographical and historical issues in education should be incorporated into theoretical models of dropout, even though such broad literatures do not specifically and exclusively focus on dropout. Understandably, when dropout researchers have paid attention to wider institutional contexts beyond peers and the family, they focus first and foremost on schools, the most proximal institutional context of dropout and the one that offers major levers for preventive actions (e.g., Wehlage et al., 1989). Yet, larger geographical and historical contexts also are relevant, as they determine the conditions under which schools themselves operate and as such may influence the immediate context in which the decision to drop out is made. Because geographical and historical aspects of dropout have often been overlooked in theoretical and empirical dropout research, related life course concepts are described and illustrated in further detail next.

Geographical contexts: Neighborhood poverty concentration. Research about neighborhood effects on youth adjustment, including in terms of educational outcomes, exploded in recent decades (for reviews, see Johnson Jr., 2010; Leventhal, Dupéré, \& Brooks-Gunn, 2009; Sampson, Morenoff, \& Gannon-Rowley, 2002). Findings from this field indicate that neighborhood characteristics might constrain or expand adolescent opportunities and shape the context in which educational decisions are made. Notably, long-term risks and precipitating factors may operate differently depending on whether the local social context is disadvantaged or 
advantaged, over and above family socio-economic status, as the following selected examples illustrate.

Neighborhood research has highlighted the range of social problems to which young people growing up in high poverty neighborhoods are exposed, which is not limited to high school dropout but also includes crime and violence, incarceration, teenage childbearing, and adolescent delinquency, among other factors (Sampson et al., 2002). This concentration of problems means that young people living in disadvantaged communities are exposed to a wide array of potential life pathways, including more conventional ones leading to high school graduation but also to many alternatives incompatible with schooling, such as engagement in early parenthood or full-time employment (Harding, 2011). It is thought that exposure to others who have chosen alternative pathways to high school graduation increase the risk of high school dropout via peer contagion processes (Crane, 1991). Thus, in communities of concentrated disadvantage, dropout could often be precipitated by various events related to this heterogeneity of pathways. For instance, dropout could happen following the birth of a child or in lockstep with the decision of a close friend or sibling to drop out. Also, because arrest and incarceration rates are disproportionately high in disadvantaged communities (Sampson \& Loeffler, 2010), events involving arrest of adolescents or their parents could trigger dropout particularly often in disadvantaged communities.

By contrast, in comparatively advantaged communities, dropout students may not so much be pulled out of school by the example of other who have dropped out before them but rather be pushed out of schools via negative evaluations of themselves in comparison to local peers who overwhelmingly succeed academically (e.g., Crosnoe, 2009; Nagengast \& Marsh, 2012). In fact, students tend to pay more attention to their relative standing within their immediate local community rather than as compared to more general segments of the population 
(Zell \& Alicke, 2009). Thus, for students who struggle academically in the context of a high achieving environment, such comparisons could breed social isolation and negative feelings about the self, others, and school. Events related to these feelings of inadequacy, including for instance internalized mental health problems, could act as triggers of dropout relatively often in comparatively advantaged communities. Struggling students in such communities may also try to compensate for feelings of academic inadequacy by heavily investing in alternative pursuits, such as work. Following a similar reasoning, Tinto (1975) proposed that among sub-groups of struggling students, the dropout rate could be higher in more advantaged contexts, as these students could come to view themselves as particularly ill-suited to academic pursuits and seek alternative activities.

Geographical context: Larger urban/rural dynamics. Concentrated disadvantage in urban neighborhoods has been at the center of research linking geographical contexts and developmental outcomes (Burton, Kemp, Leung, Matthews, \& Takeuchi, 2011; Wilson, 1987). However, other spatial dynamics operating at higher geographical levels are potentially important for understanding the process, and especially precipitating factors, of dropout. One meaningful geographical distinction is between urban and rural or small town communities. Studying the urban/rural dynamics of dropout is crucial because the rate of dropout is highest in highly disadvantaged urban neighborhoods and isolated rural areas (Lawson \& Lawson, 2013; Roscigno, Tomaskovic-Devey, \& Crowley, 2006). Despite the fact that the experience of dropping out in a disadvantaged urban neighborhood is likely to be different than in a depressed rural town (Lichter et coll., 2003; Schafft \& Jackson, 2010), very few studies have examined the particular challenges of rural students by directly comparing their experiences with those of their urban peers (Arnold, Newman, Gaddy, \& Dean, 2005; Coladarci, 2007; Semke \& Sheridan, 2012). In fact, existing models of dropout are urban-centric, overlooking the educational 
contexts of almost ten million students attending public schools in rural areas, representing $20 \%$ of the student population (Strange, Johnson, Showalter, \& Klein, 2012). This state of affairs reflects a broader neglect observed in developmental science in general (Burton, Lichter, Baker, \& Eason, 2013; Conger, 2013; Eccles \& Roeser, 2011).

To give but one example of how potential precipitating factors may vary as a function of urbanicity, being bullied might precipitate dropout more often in rural areas than in urban contexts. Even though bullying is destructive everywhere, recent evidence suggests that cases of severe peer victimization are more frequent in rural than in urban schools (Leadbeater et al., 2013), and that sexual minority youth face more hostility in rural schools than in urban ones (Kosciw, Greytak, \& Diaz, 2009). Urban and rural adolescents even may process this social stress differently based on neurological evidence (Lederbogen et al., 2011). Several factors may amplify severity in rural areas. First, when unconventional youth are singled out and bullied, they may develop particularly strong feelings of distress and isolation when they live in a relatively homogeneous and conservative environment, two common characteristics of many smaller rural communities (Crockett, Shanahan, \& Jackson-Newsom, 2000; Poon \& Saewyc, 2009). Second, bullied rural students may feel trapped, given that the recruiting territory of their high school is so large that a transfer to another school is not a realistic option. In such a context, dropping out may appear like a rational exit strategy in comparison with more radical ones such as suicide. Findings from one qualitative study support these ideas (Ferguson et al., 2005). Other indirect support includes the generally higher rates of suicide in rural areas.

Interestingly, landmark studies in both the stress process and life course traditions find that social isolation may be an important trigger for problematic behavior in small towns and rural communities. For instance, a series of classic British studies linking stressors to women’s onset of depression found that in rural areas, women who were not socially integrated into their 
community's traditional way of life were particularly vulnerable (Brown \& Prudo, 1981). Similarly, a study of family life in rural Iowa during the farm crisis of the 1980s found that adolescents from isolated families who did not fit in the local farm culture were more likely to struggle than their peers who were from families who were fully integrated (Elder \& Conger, 2000). It is interesting to note that Tinto (1975) also proposed that smaller and more homogeneous schools, despite their advantages, were likely to render social integration more difficult for non-conventional students who did not fit into the dominant culture.

Social isolation provides one example of ways in which precipitating events may play out differently in rural areas and large cities. A number of stressful events are more common among rural adolescents as compared with their urban peers, and may be especially likely to precipitate dropout in rural schools. They include injuries caused by car crashes, pregnancies, and substance abuse (Kmet \& Macarthur, 2006; Lambert, Gale, \& Hartley, 2008; National Campaign to Prevent Teen Preganancy, 2013). In addition to urban/rural differences, other forms of regional dynamics and divisions between jurisdiction, such as states and countries, could be relevant because of variations in educational policies (Lamb, Markussen, Teese, Sandberg, \& Polesel, 2011; Sampson, 2012). Clearly, there is a need for studies examining how the process leading to dropout varies as a function of geographical context.

Historical context. Staying in high school until graduation has immediate costs, as it means putting off alternative pursuits such as full-time employment. In the current labor market, bearing these costs is a long-run investment because of the higher wages associated with more years of schooling (Hout, 2012). However, the terms on which this calculation is made are likely to reflect important historical shifts in labor and educational market conditions. Almost forty years ago, Tinto (1975) observed that local job markets influenced students' decision to stay in school. Since he made this observation in the 1970s, the labor market in advanced economies has 
undergone major changes, becoming more polarized over time (Goldin \& Katz, 2009; Wilson, 1987). On the one hand, unskilled workers today face major challenges, with the rise of lowpaid, unstable service jobs and the decline of well-paid, mid-level jobs with benefits in the manufacturing and related sectors (Sum, Khatiwada, McLaughlin, \& Palma, 2011). On the other hand, skilled professionals with college degrees reap important benefits in the current knowledgebased information economy (Hout, 2012). Reflecting this reality, the proportion of adolescents from both disadvantaged and advantaged backgrounds who aspire to go to college has risen sharply (Reynolds \& Kirkpatrick Johnson, 2011; Venezia \& Jaeger, 2013). However, their high school graduation rates have not followed suit, especially among disadvantaged youth (for whom dropout remains common; Heckman \& LaFontaine, 2010). Because of this disconnect, aspirations are not as good a predictor of educational attainment as they were a few decades ago (Reynolds, Stewart, Macdonald, \& Sischo, 2006).

There are a number of ways through which the current economic and social climate may impede the fulfillment of disadvantaged students' increased educational aspirations. Even though returns to education have increased at both the high school and college levels (Heckman, Lochner, \& Todd, 2008), high school students may perceive that college is what really counts in the current context and expect low returns from high school graduation per se (Jensen, 2010; see also Manski, 1993). Thus, high school graduation may seem superfluous if one comes to think that the all-important college diploma is unattainable, a conclusion that disadvantaged students may be especially likely to reach nowadays for a number of reasons, including rising tuition and difficult access to financial aid (Ehrenberg, 2012; Oreopoulos \& Petronijevic, 2013).

In addition to these long-term trends shifting over decades, shorter-term economic cycles may impact educational decisions as well. For instance, during economic recessions, young people who can afford to may elect to stay in education longer because of the low opportunity 
costs of doing so when the job market is depressed. In contrast, students whose families are hit harder may exit education more rapidly to support themselves in the short term. Consistent with this hypothesis, empirical findings show that educational inequality as a function of family socioeconomic status increases in times of economic crisis (e.g., Shanahan, Miech, \& Elder, 1998; Torche, 2010).

Historical forces are dynamic and it is important to acknowledge that emerging trends may further shape the perceived value of high school and college degrees. For example, economists forecasted major changes in the dynamics of educational markets as a result of the growing share of alternative educational options via online education and elearning, including at the K-12 level (Cowen, 2013). With the rise of online education, alternative educational routes will continue to open up and change the educational landscape at all levels (Barrow, Brock, \& Rouse, 2013). These major shifts are likely to alter pathways to high school dropout and graduation in meaningful (if difficult to predict) ways, and models of dropout should recognize the potential influence of such historical shifts.

\section{Integrative Stress Process, Life Course Model of Dropout}

Theoretical integration. Based on the relevant elements of the stress process and life course perspective highlighted in the previous sections, Figure 1 presents an integration of these two models in relation to dropout. Echoing leading theories of high school dropout, both the stress process and life course models underscore the importance of predisposing factors and vulnerabilities and past social experiences. These elements are captured in the left-hand part of Figure 1, where previous individual characteristics (both stable and changing) as well as cumulative exposure to major developmental contexts (defined by their structural and process characteristics) set the backdrop in which future high school experiences should be understood. 
The individual and contextual variables listed reflect findings from comprehensive reviews of risk factors associated with dropout (Rumberger, 2011).

The stress process and life course perspectives put equal emphasis on the continuity of long-term influences and the discontinuities brought about by contemporary stressors and turning points. In this respect, life course and stress process models differ from major dropout theories, which have on the whole paid less attention to precipitating factors, even while recognizing their potential role. The upper right-hand part of Figure 1 provides examples of proximal stressors emerging in high school that could constitute turning points in precipitating dropout. The list is not exhaustive but broadly covers the limited evidence currently available. It distinguishes between events affecting youth and significant others in recognition of the life course concept of linked lives. The lower right-hand part of Figure 1 presents internal and external protective factors identified in the stress process (e.g., coping repertoires), life course (e.g., agency), and dropout (e.g., school supports) literature. These factors are expected to moderate the impact of stressors on youth’s educational trajectories.

Reflecting the complexities embedded in all of the models discussed, Figure 1 shows how long-term risk factors, as well as proximal precipitating stressors and supports, come together to generate the complex outcome of dropout. The converging arrows bringing together predisposing and precipitating factors depict this complexity. They indicate that these factors can combine in additive, interactive, and dynamic ways, thus giving rise to complex feedback loops captured in terms like stress generation or differential susceptibility. The arrows are also meant to show that such interplays may occur within a class of factors. For instance, precipitating factors may operate jointly, with protective factors present in high school moderating the impact of contemporary stressors. Complex interactions may occur even within one type of predisposing or precipitating factors. For instance, stress proliferation suggests that multiple stressors may add 
up and potentiate each other's effect when particularly problematic configurations of stressors are present.

The emergence of precipitating stressors does not necessarily result in immediate dropout. Rather, it is expected that when new stressors arise, attendance will drop, in turn leading to failure and rapid disengagement and, ultimately, dropout. Such proximal mediators are represented in the right half of the figure.

Finally, the full interplay between and within distal and proximal factors is presented as being shaped by overarching historical and geographical dynamics, in accordance with the life course perspective, and by socioeconomic factors that influence the (often unequal) distribution of stressors across groups, as highlighted by stress process work. Moreover, developmental timing is depicted as a major structuring factor at the bottom of the figure, distinguishing predisposing factors and long-term risks from proximal precipitating factors emerging in high school months or weeks before the decision to dropout is made.

Methodological recommendations. As noted in the section reviewing relevant empirical dropout studies, methodological shortcomings of common study designs have limited our ability to assess the interplay of enduring risks and contemporary stressors and turning points in relation to dropout. Moreover, the wider context in which these processes occur needs to be considered. To address these problems, the stress process and life course research traditions are highly informative. These research traditions have used innovative methodological tools when faced with similar problems associated with the joint and contextualized consideration of early and contemporary risk factors. These tools could help push forward our understanding of the dropout process.

To allow for the integration of both distal and proximal risk factors, a particularly promising approach consists of combining the strengths of two common designs in dropout 
research, longitudinal surveys and detailed interviews with recent dropouts. For instance, contrasted subgroups could be selected from wider longitudinal studies for in-depth interviews about life circumstances while in high school. These subsamples could include not only recent dropouts but also carefully matched comparison students who remain in school. One example of a study using such an approach based on a life course framework was conducted by Laub and Sampson (2003) in the field of criminology. They selected a subset of contrasted cases exhibiting different criminal outcomes in adulthood among a sample of about 500 juvenile delinquents followed from childhood up until old age. These cases were invited for in-depth semi-structured interviews, during which life history calendars were used to describe and date all major events and turning points they experienced in their adult lives. These events were then related to their criminal history, while accounting for their initial profile of risk. Such alternative mixed study designs have been used to gain a broader understanding of a number of important social problems (see Small, 2011) and could fruitfully be applied in studies about the dropout process, assuming an adequate rate of participation. Dropouts, like juvenile delinquents, are notoriously hard to recruit in research projects, as evidenced by participation rates routinely below 30\% with such high risk populations (e.g., Heinrichs, Bertram, Kuschel, \& Hahlweg, 2005). Despite important recruiting challenges, Laub and Sampson (2003) were able to interview about $60 \%$ of the men they contacted, by personalizing communications with participants, by offering monetary compensations, and by being flexible regarding time, place, and means (in person or by phone) for the interviews. Using similar techniques in an ongoing project, we found that recent dropouts agree to participate in interviews at about the same rate.

In similar mixed-methods studies focusing on the precipitants of dropout, interview methods designed to cover relatively short time frames of up to a year would be indicated. In the stress process tradition, such interview schedules have been validated and shown to reliably 
represent a wide range of stressful situations experienced by both adults and adolescents (Duggal et al., 2000; Monroe, 2008). These interview schedules were developed by researchers interested in the precipitating role of stressors in the onset of mental health problems, but they could be applied to study educational outcomes that also may be shaped by immediate stressful circumstances, such as dropout.

Beyond study designs and measures, other methodological tools used in stress process and life course research are also enlightening, notably when it comes to data analysis and statistical modeling. In this respect, the life course paradigm galvanized the development and application in new contexts of many analytical tools allowing for the examination of continuity and change, while also incorporating contextual and historical considerations. These tools include event history analysis, which has long played a central role in life course research (Mayer \& Tuma, 1990), but also growth curves and trajectory analysis, multilevel modeling, sequence analysis, as well as generational and age-period-cohort analysis (Aisenbrey \& Fasang, 2010; Cohen, 2008; George, 2009; Giele \& Elder, 1998; Mortimer \& Shanahan, 2003; Yang \& Land, 2008).

Although a description of these techniques is beyond the scope of this article, it is relevant to note that this varied collection of analytical tools makes it possible to examine how the core elements of the life course paradigm exert their role in the generation of important life outcomes, such as high school dropout. Thus, the potential contribution of the stress process and life course traditions to dropout research is not limited to theoretical insights; it also includes important methodological aspects in terms of study design, measures, and analysis.

\section{Policy Implications}

Without a high school diploma, young people’s long-term prospects are severely diminished for virtually every valued life outcome, including mental and physical health as well as employment stability and lifetime productivity and earnings (Rumberger, 2011). These 
consequences are likely to be felt especially strongly in advanced economies where even jobs traditionally considered as unskilled increasingly demand considerable literacy and digital skills (OECD, 2013). Thus, in recent decades high school dropout has captured the attention of policy makers, philanthropists, and researchers alike. Major investments by these groups have led to important advances in terms of understanding dropout. Yet, despite these investments and recent improvements, graduation rates have been stubbornly slow to improve in the United States (Heckman \& LaFontaine, 2010; Murnane, 2013; Rumberger, 2011).

These setbacks arise even though relatively effective preventive approaches exist to address both early and contemporary risk factors. In terms of early risks, high-quality preschool programs have been found to reduce dropout (Duncan \& Magnuson, 2013). For instance, a landmark study evaluating the Perry Preschool program for disadvantaged children found that $60 \%$ of children in the control group graduated from high school, whereas $77 \%$ of the intervention group did so (Schweinhart et al., 2005). Thus, despite significant gains, about a quarter of those who received this high-quality, intensive preschool program for two full years did not graduate from high school. Even model preschool programs are insufficient and need to be complemented by high-quality services offered at other critical junctions during the K-12 years, notably during high school, when dropout occurs (Brooks-Gunn, 2003).

During high school, two types of preventive approaches are associated with reduced risks for dropout: targeted programs focusing on high-risk youth and wider school reforms aimed at whole populations of students. Once again, despite their strengths, both approaches have problems that limit their usefulness, especially on a large scale. Targeted programs can be effective among the small group of selected high-risk students who they serve (Wilson, TannerSmith, Lipsey, Steinka-Fry, \& Morrison, 2011); however, these programs are irrelevant for students who drop out but do not present to school personnel as particularly at risk. Such "quiet" 
dropouts represent a significant proportion of the dropout population (e.g., Bowers \& Sprott, 2012a; Janosz et al., 2000). Whole-school programs cast a broader net and have a greater chance to reach all vulnerable students, but these programs are hard to implement, maintain, and scale up, especially in the very places where they are most needed (Holme \& Rangel, 2012; Schneider \& McDonald, 2007).

Addressing the dropout problem is exceedingly complex, and no single approach is a panacea. One way to improve the effectiveness of existing preventive approaches implemented during high school would be to better match targeted programs to the specific needs of individual students and universal programs to the shared needs of local students (Bloom, 2010; Bloom et al., 2010; Wehlage et al., 1989). To do so, a contextualized understanding of the heterogeneous routes leading to dropout is necessary. This understanding should include increased knowledge of the role of precipitating factors to address the needs of those who drop out in response to such factors. It should also include increased knowledge of how the routes to dropout vary as a function of local contexts. The conclusions of a recent meta-analysis are telling in this regard (Wilson et al., 2011). After reviewing more than 500 individual publications about dropout prevention and intervention programs, the authors observed that no single program emerged as being consistently more effective than any other program. In light of the minimal variation in efficacy they observed across program types, the authors concluded that high school administrators would be wise to select programs that are best align with their students' needs, given their specific local context. However, because current theoretical models of dropout and related empirical research have largely ignored variations as a function of local contexts, especially when it comes to the proximal precipitants of dropout, high school administrators often must rely on their best educated guess in selecting the most relevant program for their specific 
context. It is hoped that the conceptual model of dropout outlined here could stimulate future research to fill in this gap.

\section{Concluding Remarks}

Leading theorists of high school dropout noted decades ago that students drop out for different reasons. In many cases, dropout is best described as the end point of long histories of academic and behavioral difficulties. However, this pathway out of school is by no means universal. For a substantial proportion of students, the decision to leave school comes in response to numerous contemporary stressors or opportunities incompatible with school. Despite acknowledging the relevance of proximal circumstances, existing models of high school dropout have not elaborated on the precipitating role of events and difficulties emerging late in students' schooling careers, just before the decision to drop out is made. Echoing this theoretical void, few empirical studies have been conducted on this issue. To fill this gap, this article proposes a theoretical perspective that bridges existing dropout models with concepts from two general models of human development, the stress process and life course frameworks, which comprise a dual focus on long-term experiences and contemporary circumstances. It is hoped that this effort will provide new theoretical and methodological tools to examine, and ultimately address, the old problem of high school dropout. 


\section{References}

Aisenbrey, S., \& Fasang, A. E. (2010). New life for old ideas: The "second wave" of sequence analysis bringing the "course" back into the life course. Sociological Methods \& Research, 38(3), 420-462. doi: 10.1177/0049124109357532

Alexander, K. L., Entwisle, D. R., \& Kabbani, N. (2001). The dropout process in life course perspective: Early risk factors at home and school. Teachers College Record, 103, 760822. doi: 10.1111/0161-4681.00134

Amato, P. R. (2010). Research on divorce: Continuing trends and new developments. Journal of Marriage and Family, 72(3), 650-666. doi: 10.1111/j.1741-3737.2010.00723.x

America’s Promise Alliance and its Center for Promise. (2014). Don't call them dropouts: Understanding the experiences of young people who leave high school before graduation. Washington, DC: America’s Promise Alliance and its Center for Promise.

Arnold, M. L., Newman, J. H., Gaddy, B. B., \& Dean, C. B. (2005). A look at the condition of rural education research: Setting a difference for future research. Journal of Research in Rural Education, 20, 1-25.

Ashcraft, A., Fernández-Val, I., \& Lang, K. (2013). The consequences of teenage childbearing: Consistent estimates when abortion makes miscarriage non-random. The Economic Journal, 571, 875-905. doi: 10.1111/ecoj.12005

Avison, W. R. (2010). Incorporating children's lives into a life course perspective on stress and mental health. Journal of Health and Social Behavior, 51, 361-375. doi: $10.1177 / 0022146510386797$

Barrow, L., Brock, T., \& Rouse, C. E. (2013). Postsecondary education in the United States: Introducing the issue. The Future of Children, 23, 3-16. doi: 10.1353/foc.2013.0006 
Barry, M., \& Reschly, A. L. (2012). Longitudinal predictors of high school completion. School Psychology Quarterly, 27(2), 74. doi: 10.1037/a0029189

Battin-Pearson, S., Newcomb, M. D., Abbott, R. D., Hill, K. G., Catalano, R. F., \& Hawkins, J. (2000). Predictors of early high school dropout: A test of five theories. Journal of Educational Psychology, 92, 568. doi: 10.1037//0022-0663.92.3.568

Beekhoven, S., \& Dekkers, H. (2005). Early school leaving in the lower vocational track: triangulation of qualitative and quantitative data. Adolescence, 40, 197-213.

Belsky, J., \& Pluess, M. (2009). Beyond diathesis stress: Differential susceptibility to environmental influences. Psychological Bulletin, 135(6), 885. doi: 10.1037/a0017376

Berktold, J., Geis, S., \& Kaufman, P. (1998). Subsequent educational attaintment of high school dropouts. Washington, D.C.: U.S. Department of Education.

Blair, C., \& Raver, C. C. (2012). Child development in the context of adversity: Experiential canalization of brain and behavior. American Psychologist, 67, 309-318. doi: 10.1037/a0027493

Bloom, D. (2010). Programs and policies to assist high school dropouts in the transition to adulthood. The Future of Children, 20(1), 89-108. doi: 10.1353/foc.0.0039

Bloom, D., Thompson, S. L., \& Ivry, R. (2010). Building a learning agenda around disconnected youth. New York: MDRC.

Bowers, A. J. (2010). Grades and graduation: A longitudinal risk perspective to identify student dropouts. The Journal of Educational Research, 103(3), 191-207. doi: $10.1080 / 00220670903382970$

Bowers, A. J., \& Sprott, R. (2012a). Examining the multiple trajectories associated with dropping out of high school: A growth mixture model analysis. The Journal of Educational Research, 105(3), 176-195. doi: 10.1080/00220671.2011.552075 
Bowers, A. J., \& Sprott, R. (2012b). Why tenth graders fail to finish high school: A dropout typology latent class analysis. Journal of Education for Students Placed at Risk (JESPAR), 17(3), 129-148. doi: 10.1080/10824669.2012.692071

Bowers, A. J., Sprott, R., \& Taff, S. A. (2013). Do we know who will drop out?: A review of the predictors of dropping out of high school: Precision, sensitivity, and specificity. The High School Journal, 96, 77-100.

Breslau, J. (2010). Health in childhood and adolescence and high school dropout (Report \#17). Davis: California Dropout Research Project, University of California.

Bridgeland, J. M., Dilulio, J. J., Jr., \& Morison, K. B. (2006). The silent epidemic: Perspectives of high school dropouts. Washington, D.C.: Civic Enterprises in association with Peter D. Hart Research Associates for the Bill \& Melinda Gates Foundation.

Bronfenbrenner, U., \& Morris, P. A. (2006). The bioecological model of human development. In W. Damon \& R. M. Lerner (Eds.), Handbook of Child Psychology (6th ed., Vol. 1, pp. 793-828). New York: Wiley.

Brooks-Gunn, J. (2003). Do you believe in magic?: What we can expect from early childhood intervention programs. Society for Research in Child Development (SRCD) Social Policy Report, 17, 3-14.

Brown, G. W., \& Prudo, R. (1981). Psychiatric disorder in a rural and an urban population: 1. Aetiology of depression. Psychological Medicine, 11, 581-599. doi: $10.1017 /$ S0033291700052880

Burton, L. M., Kemp, S. P., Leung, M., Matthews, S. A., \& Takeuchi, D. T. (2011). Communities, Neighborhoods, and Health: Expanding the Boundaries of Place. New York: Springer. 
Burton, L. M., Lichter, D. T., Baker, R. S., \& Eason, J. M. (2013). Inequality, family processes, and health in the "new” rural America. American Behavioral Scientist, 57, 1128-1151. doi: $10.1177 / 0002764213487348$

Cavanagh, S. E., \& Fomby, P. (2012). Family instability, school context, and the academic careers of adolescents. Sociology of Education, 85, 81-97. doi: $10.1177 / 0038040711427312$

Cavanagh, S. E., Schiller, K. S., \& Riegle-Crumb, C. (2006). Marital transitions, parenting, and schooling: Exploring the link between family-structure history and adolescents' academic status. Sociology of Education, 79, 329-354. doi: 10.1177/003804070607900403

Cho, R. M. (2011). Understanding the mechanism behind maternal imprisonment and adolescent school dropout. Family Relations, 60, 272-289. doi: 10.1111/j.1741-3729.2011.00649.x

Christenson, S. L., \& Thurlow, M. L. (2004). School dropouts: Prevention considerations, interventions, and challenges. Current Directions in Psychological Science, 13(1), 36-39.

Cicchetti, D., \& Rogosch, F. A. (2002). A developmental psychopathology perspective on adolescence. Journal of Consulting and Clinical Psychology, 70(1), 6. doi: 10.1037//0022-006X.70.1.6

Clandinin, D. J., Steeves, P., \& Caine, V. (2013). Composing lives in transition: A narrative inquiry into the experiences of early school leavers. Bingley, UK: Emerald Group Publishing Limited.

Cohen, P. (2008). Applied data analytic techniques for turning points research. New York, NY: Routledge.

Coladarci, T. (2007). Improving the yield of rural education research: An editor's swan song. Journal of Research in Rural Education, 22, 22-23. 
Conger, R. D. (2013). Rural children at risk. Monographs of the Society for Research in Child Development, 78, 127-138. doi: 10.1111/mono.12055

Conger, R. D., Conger, K. J., \& Martin, M. J. (2010). Socioeconomic status, family processes, and individual development. Journal of Marriage and Family, 72, 685-704. doi: 10.1111/j.1741-3737.2010.00725.x

Cowen, T. (2013). Average is over: Powering america beyond the age of the great stagnation. New York: Penguin.

Crane, J. (1991). The epidemic theory of ghettos and neighborhood effects on dropping out and teenage childbearing. American Journal of Sociology, 96, 1126-1159.

Crockett, L. J., Shanahan, M. J., \& Jackson-Newsom, J. (2000). Rural youth: Ecological and life course perspectives. In R. Montemayor, G. R. Adams \& T. P. Gullotta (Eds.), Adolescent Diversity in Ethnic, Economic, and Cultural Contexts: Advances in Adolescent Development (Vol. 10, pp. 43-74). Thousand Oaks, CA: Sage Publications.

Crosnoe, R. (2009). Low-income students and the socioeconomic composition of public high schools. American Sociological Review, 74, 709-730. doi: 10.1177/000312240907400502

Crosnoe, R., \& Johnson, M. K. (2011). Research on adolescence in the twenty-first century. Annual Review of Sociology, 37, 439-460. doi: 10.1146/annurev-soc-081309-150008

Dalton, B., Glennie, E., \& Ingels, S. J. (2009). Late high school dropouts: Characteristics, experiences, and changes across cohorts. Washington, DC: National Center for Education Statistics, Institute of Education Sciences, U.S. Department of Education.

Dobbie, W., \& Fryer, R. G., Jr. (2011). Are high-quality schools enough to increase achievement among the poor? Evidence from the Harlem Children's Zone. American Economic Journal: Applied Economics, 3, 158-187. doi: 10.1257/app.3.3.158 
Duchesne, S., Vitaro, F., Larose, S., \& Tremblay, R. E. (2008). Trajectories of anxiety during elementary-school years and the prediction of high school noncompletion. Journal of Youth and Adolescence, 37, 1134-1146. doi: 10.1007/s10964-007-9224-0

Duggal, S., Malkoff-Schwartz, S., Birmaher, B., Anderson, B., Matty, M. K., Houck, P. R., .. . Frank, E. (2000). Assessment of life stress in adolescents: Self-report versus interview methods. Journal of the American Academy of Child \& Adolescent Psychiatry, 39, 445452. doi: 10.1097/00004583-200004000-00013

Duncan, G. J., \& Magnuson, K. (2013). Investing in Preschool Programs. The Journal of Economic Perspectives, 27(2), 109-132. doi: 10.1257/jep.27.2.109

Eccles, J. S., \& Roeser, R. W. (2011). Schools as developmental contexts during adolescence. Journal of Research on Adolescence, 21(1), 225-241. doi: 10.1111/j.15327795.2010.00725.x

Ehrenberg, R. G. (2012). American higher education in transition. The Journal of Economic Perspectives, 26, 193-216. doi: 10.1257/jep.26.1.193

Elder, G. H., \& Conger, R. D. (2000). Children of the land: Adversity and success in rural America: University of Chicago Press.

Elder, G. H., Jr. (1999). Children of the great depression: Social change in life experience (25th Anniversary ed.). Boulder, CO: Westview Press.

Elder, G. H., Jr, George, L. K., \& Shanahan, M. J. (1996). Psychosocial stress over the life course. In H. B. Kaplan (Ed.), Psychosocial Stress: Perspectives on Structure, Theory, Life-Course, and Methods (pp. 247-292). New York: Cambridge University Press.

Elder, G. H., Jr, \& Giele, J. (2009). Life course studies: An evolving field The craft of life course research (pp. 1-24). New York: Guilford Press. 
Elder, G. H., Jr. (1986). Military times and turning points in men's lives. Developmental Psychology, 22, 233. doi: 10.1037/0012-1649.22.2.233

Elder, G. H., Jr. (1998). The life course as developmental theory. Child Development, 69(1), 112.

Entwisle, D. R., Alexander, K. L., \& Olson, L. S. (2005). First grade and educational attainment by age 22: A new story. American Journal of Sociology, 110(5), 1458-1502. doi:

\section{$10.1086 / 428444$}

Evans, G. W., \& Cassells, R. C. (2014). Childhood poverty, cumulative risk exposure, and mental health in emerging adults. Clinical Psychological Science, Advance online publication. doi: $10.1177 / 2167702613501496$

Evans, G. W., \& Schamberg, M. A. (2009). Childhood poverty, chronic stress, and adult working memory. Proceedings of the National Academy of Sciences, 106(16), 6545-6549. doi: 10.1073/pnas.0811910106

Feinstein, L., \& Peck, S. C. (2008). Unexpected pathways through education: Why do some students not succeed in school and what helps others beat the odds? Journal of Social Issues, 64(1), 1-20. doi: 10.1111/j.1540-4560.2008.00545.x

Ferguson, B., Tilleczek, K., Boydell, K., \& , \& Rummens, J. (2005). Early school leavers: Understanding the lived reality of student disengagement from secondary school. Toronto, ON: Ontario Ministry of Education.

Finn, J. D. (1989). Withdrawing from school. Review of Educational Research, 59(2), 117-142. doi: $10.3102 / 00346543059002117$

Fletcher, J. M., \& Wolfe, B. L. (2009). Education and labor market consequences of teenage childbearing: Evidence using the timing of pregnancy outcomes and community fixed effects. Journal of Human Resources, 44(2), 303-325. doi: 10.3368/jhr.44.2.303 
Flouri, E., \& Kallis, C. (2007). Adverse life events and psychopathology and prosocial behavior in late adolescence: Testing the timing, specificity, accumulation, gradient, and moderation of contextual risk. Journal of the American Academy of Child \& Adolescent Psychiatry, 46, 1651-1659. doi: 10.1097/chi.0b013e318156a81a

Fomby, P., \& Bosick, S. J. (2013). Family instability and the transition to adulthood. Journal of Marriage and Family, 75, 1266-1287. doi: 10.1111/jomf.12063

Gasper, J., De Luca, S., \& Estacion, A. (2012). Switching schools: Revisiting the relationship between school mobility and high school dropout. American Educational Research Journal, 49, 487-519 doi: 10.3102/0002831211415250

George, L. K. (2009). Conceptualizing and measuring trajectories. In G. H. Elder, Jr \& J. Giele (Eds.), The craft of life course research (pp. 163-186). New York, NY: Guilford Press. George, L. K. (2013). Life-course perspectives on mental health. In C. S. Aneshenzel, J. C. Phelan \& A. Bierman (Eds.), Handbook of the Sociology of Mental Health (2nd ed., pp. 585-602). Dordrecht, Netherlands: Springer.

Giele, J. Z., \& Elder, G. H. (1998). Methods of life course research: Qualitative and quantitative approaches. Thousand Oaks, CA: Sage.

Goldin, C. D., \& Katz, L. F. (2009). The race between education and technology. Cambridge, MA: Harvard University Press.

Hagan, J., \& Foster, H. (2012). Children of the American prison generation: Student and school spillover effects of incarcerating mothers. Law \& Society Review, 46(1), 37-69. doi: 10.1111/j.1540-5893.2012.00472.x

Hammen, C. (2006). Stress generation in depression: Reflections on origins, research, and future directions. Journal of Clinical Psychology, 62, 1065-1082. doi: 10.1002/jclp.20293 
Hankin, B. L. (2012). Future directions in vulnerability to depression among youth: Integrating risk factors and processes across multiple levels of analysis. Journal of Clinical Child \& Adolescent Psychology, 41(5), 695-718. doi: 10.1080/15374416.2012.711708

Hankin, B. L., \& Abela, J. R. Z. (2005). Development of psychopathology: A vulnerability-stress perspective Thousand Oaks, CA: Sage Publications.

Harding, D. J. (2011). Rethinking the cultural context of schooling decisions in disadvantaged neighborhoods: From deviant subculture to cultural heterogeneity. Sociology of Education, 84, 322-339. doi: 10.1177/0038040711417008

Harris, K. (2012). The Add Health Study:Design and Accomplishments. Chapel Hill, NC: Carolina Population Center, University of North Carolina at Chapel Hill.

Heckman, J. J., \& LaFontaine, P. A. (2010). The American high school graduation rate: Trends and levels. The Review of Economics and Statistics, 92(2), 244-262. doi: 10.1162/rest.2010.12366

Heckman, J. J., Lochner, L. J., \& Todd, P. E. (2008). Earnings functions and rates of return. Journal of Human Capital, 2(1), 1-31. doi: 10.1086/587037

Heinrichs, N., Bertram, H., Kuschel, A., \& Hahlweg, K. (2005). Parent recruitment and retention in a universal prevention program for child behavior and emotional problems: Barriers to research and program participation. Prevention Science, 6(4), 275-286. doi: 10.1007/s11121-005-0006-1

Hirschfield, P. J. (2009). Another way out: The impact of juvenile arrests on high school dropout. Sociology of Education, 82, 368-393. doi: 10.1177/003804070908200404

Holme, J. J., \& Rangel, V. S. (2012). Putting school reform in its place: Social geography, organizational social capital, and school performance. American Educational Research Journal, 49(2), 257-283. doi: 10.3102/0002831211423316 
Homlong, L., Rosvold, E. O., \& Haavet, O. R. (2013). Can use of healthcare services among 1516-year-olds predict an increased level of high school dropout? A longitudinal community study. BMJ Open, 3(9), e003125. doi: 10.1136/bmjopen-2013-003125

Hout, M. (2012). Social and economic returns to college education in the United States. Annual Review of Sociology, 38, 379-400. doi: 10.1146/annurev.soc.012809.102503

Ingram, R. E., \& Luxton, D. D. (2005). Vulnerability-stress models. In B. L. Hankin \& J. R. Z. Abela (Eds.), Development of psychopathology: A vulnerability-stress perspective (pp. 32-46). Thousand Oaks, CA: Sage Publications.

Janosz, M., Archambault, I., Morizot, J., \& Pagani, L. S. (2008). School engagement trajectories and their differential predictive relations to dropout. Journal of Social Issues, 64, 21-40. doi: 10.1111/j.1540-4560.2008.00546.x

Janosz, M., Le Blanc, M., Boulerice, B., \& Tremblay, R. E. (2000). Predicting different types of school dropouts: A typological approach with two longitudinal samples. Journal of Educational Psychology, 92, 171-190. doi: 10.1037//0022-0663.92.1.171

Jensen, R. (2010). The (perceived) returns to education and the demand for schooling. The Quarterly Journal of Economics, 125(2), 515-548. doi: 10.1162/qjec.2010.125.2.515

Jessor, R. (1998). New perspectives on adolescent risk behavior. Cambridge, UK: Cambridge University Press.

Jimerson, S., \& Brown, J. A. (2013). Grade retention. In J. Hattie \& E. M. Anderman (Eds.), International guide to student achievement (pp. 140-142). New York: Routeledge.

Jimerson, S., Egeland, B., Sroufe, L. A., \& Carlson, B. (2000). A prospective longitudinal study of high school dropouts examining multiple predictors across development. Journal of School Psychology, 38, 525-549. doi: 10.1016/S0022-4405(00)00051-0 
Johnson Jr., O. (2010). Assessing neighborhood racial segregation and macroeconomic effects in the education of African Americans. Review of educational research, 80(4), 527-575. doi: $10.3102 / 0034654310377210$

Kirk, D. S. (2009). A natural experiment on residential change and recidivism: Lessons from Hurricane Katrina. American Sociological Review, 74, 484-505. doi: $10.1177 / 000312240907400308$

Kirk, D. S., \& Sampson, R. J. (2013). Juvenile arrest and collateral educational damage in the transition to adulthood. Sociology of Education, 86, 36-62. doi: $10.1177 / 0038040712448862$

Kirkpatrick Johnson, M., Crosnoe, R., \& Elder, G. H. (2011). Insights on adolescence from a life course perspective. Journal of Research on Adolescence, 21, 273-280. doi:

10.1111/j.1532-7795.2010.00728.x

Kmet, L., \& Macarthur, C. (2006). Urban-rural differences in motor vehicle crash fatality and hospitalization rates among children and youth. Accident Analysis \& Prevention, 38, 122127. doi: 10.1016/j.aap.2005.07.007

Kosciw, J., Greytak, E., \& Diaz, E. (2009). Who, what, where, when, and why: Demographic and ecological factors contributing to hostile school climate for lesbian, gay, bisexual, and transgender youth. Journal of Youth and Adolescence, 38, 976-988. doi: 10.1007/s10964009-9412-1

Lamb, S., Markussen, E., Teese, R., Sandberg, N., \& Polesel, J. (2011). School dropout and completion: International comparative studies in theory and policy. Dordrecht, Netherlands: Springer. 
Lambert, D., Gale, J. A., \& Hartley, D. (2008). Substance abuse by youth and young adults in rural America. The Journal of Rural Health, 24, 221-228. doi: 10.1111/j.17480361.2008.00162.x

Lamote, C., Van Damme, J., Van Den Noortgate, W., Speybroeck, S., Boonen, T., \& de Bilde, J. (2012). Dropout in secondary education: an application of a multilevel discrete-time hazard model accounting for school changes. Quality \& Quantity, 1-22. doi: 10.1007/s11135-012-9662-y

Laub, J. H., \& Sampson, R. J. (2003). Shared beginnings, divergent lives: Delinquent boys to age 70. Cambridge, MA: Harvard University Press.

Lawson, M. A., \& Lawson, H. A. (2013). New conceptual frameworks for student engagement research, policy, and practice. Review of Educational Research, 83, 432-479. doi: $10.3102 / 0034654313480891$

Leadbeater, B. J., Sukhawathanakul, P., Smith, A., Yeung Thompson, R. S., Gladstone, E. J., \& Sklar, N. (2013). Bullying and victimization in rural schools: Risks, reasons, and responses. Journal of Rural and Community Development, 8, 31-47.

Lederbogen, F., Kirsch, P., Haddad, L., Streit, F., Tost, H., Schuch, P., . . . Deuschle, M. (2011). City living and urban upbringing affect neural social stress processing in humans. Nature, 474, 498-501. doi: 10.1038/nature10190

Lee, J. C., \& Staff, J. (2007). When work matters: The varying impact of work intensity on high school dropout. Sociology of Education, 80, 158-178. doi: 10.1177/003804070708000204

Lessard, A., Butler-Kisber, L., Fortin, L., Marcotte, D., Potvin, P., \& Royer, É. (2008). Shades of disengagement: high school dropouts speak out. Social Psychology of Education, 11, 2542. doi: 10.1007/s11218-007-9033-z 
Leventhal, T., Dupéré, V., \& Brooks-Gunn, J. (2009). Neighborhood influences on adolescent development. In R. M. Lerner \& L. Steinberg (Eds.), Handbook of Adolescent Psychology (3rd ed., Vol. 2, pp. 411-443). Hoboken, NJ: Wiley.

Li, M. (2007). Bayesian proportional hazard analysis of the timing of high school dropout decisions. Econometric Reviews, 26, 529-556. doi: 10.1080/07474930701509416

Lichter, D., Roscigno, V. J., \& Condron, D. (2003). Rural children and youth at risk. In D. Brown \& L. E. Swanson (Eds.), Challenges for rural America in the twenty-first century (pp. 97108). University Park, PA: Pennsylvania State University Press.

Liu, R. T., \& Alloy, L. B. (2010). Stress generation in depression: A systematic review of the empirical literature and recommendations for future study. Clinical Psychology Review, 30(5), 582-593. doi: 10.1016/j.cpr.2010.04.010

Manski, C. F. (1993). Adolescent econometricians: How do youth infer the returns to schooling? Studies of supply and demand in higher education (pp. 43-60). Chicago, IL: University of Chicago Press.

Mayer, K. U., \& Tuma, N. B. (1990). Event history analysis in life course research. Madison, WI: University of Wisconsin Press.

McGee, L., \& Newcomb, M. D. (1992). General deviance syndrome: Expanded hierarchical evaluations at four ages from early adolescence to adulthood. Journal of Consulting and Clinical Psychology, 60, 766. doi: 10.1037/0022-006X.60.5.766

Metz, G. W. (2004). Challenge and changes to Tinto's persistence theory: A historical review. Journal of College Student Retention: Research, Theory and Practice, 6, 191-207.

Moffitt, T. E. (2008). A review of research on the taxonomy of life-course persistent versus adolescence-limited antisocial behavior. In F. T. Cullen, J. P. Wright \& K. R. Blevins 
(Eds.), Taking stock: The status of criminological theory (Vol. 15, pp. 277). New Brunswick, NJ: Transaction Publishers.

Moffitt, T. E. (1993). Adolescence-limited and life-course-persistent antisocial behavior: a developmental taxonomy. Psychological Review, 100, 674. doi: 10.1037/0033295X.100.4.674

Monahan, K. C., Lee, J. M., \& Steinberg, L. (2011). Revisiting the impact of part-time work on adolescent adjustment: Distinguishing between selection and socialization using propensity score matching. Child Development, 82, 96-112. doi: 10.1111/j.14678624.2010.01543.x

Monroe, S. M. (2008). Modern approaches to conceptualizing and measuring human life stress. Annual Review of Clinical Psychology, 4, 33-52. doi: 10.1146/annurev.clinpsy.4.022007.141207

Monroe, S. M., \& Harkness, K. L. (2005). Life stress, the" kindling" hypothesis, and the recurrence of depression: considerations from a life stress perspective. Psychological Review, 112, 417. doi: 10.1037/0033-295X.112.2.417

Morris, M. C., Ciesla, J. A., \& Garber, J. (2010). A prospective study of stress autonomy versus stress sensitization in adolescents at varied risk for depression. Journal of Abnormal Psychology, 119, 341. doi: 10.1037/a0019036

Mortimer, J. T., \& Shanahan, M. J. (2003). Handbook of the life course. New York: Springer. Murnane, R. J. (2013). U.S. high school graduation rates: Patterns and explanations. Journal of Economic Literature, 51, 370-422. doi: 10.1257/jel.51.2.370

Murray, J., \& Farrington, D. P. (2008). The effects of parental imprisonment on children. Crime and Justice, 37, 133-206. doi: 10.1086/520070 
Nagengast, B., \& Marsh, H. W. (2012). Big fish in little ponds aspire more: Mediation and crosscultural generalizability of school-average ability effects on self-concept and career aspirations in science. Journal of Educational Psychology, 104, 1033-1053.

National Campaign to Prevent Teen and Unplanned Pregnancy. (2013). Teen childbearing in rural America. Washington, DC: The National Campaign to Prevent Teen and Unplanned Pregnancy.

OECD. (2013). Education at a Glance 2013: OECD Indicators. Paris, France: OECD Publishing. Oreopoulos, P., \& Petronijevic, U. (2013). Making college worth it: A review of the returns to higher education. The Future of Children, 23(1), 41-65.

Pearlin, L. I. (2010). The life course and the stress process: Some conceptual comparisons. The Journals of Gerontology Series B: Psychological Sciences and Social Sciences, 65(2), 207-215. doi: 10.1093/geronb/gbp106

Pearlin, L. I., \& Bierman, A. (2013). Current issues and future directions in research into the stress process. In C. S. Aneshenzel, J. C. Phelan \& A. Bierman (Eds.), Handbook of the sociology of mental health (2nd ed., pp. 325-340). Dordrecht, Netherlands: Springer.

Plank, S. B., DeLuca, S., \& Estacion, A. (2008). High school dropout and the role of career and technical education: A survival analysis of surviving high school. Sociology of Education, 81, 345-370. doi: 10.1177/003804070808100402

Poon, C. S., \& Saewyc, E. M. (2009). Out yonder: Sexual-minority adolescents in rural communities in British Columbia. American Journal of Public Health, 99(1). doi: 10.2105/AJPH.2007.122945

Porche, M. V., Fortuna, L. R., Lin, J., \& Alegria, M. (2011). Childhood trauma and psychiatric disorders as correlates of school dropout in a national sample of young adults. Child Development, 82(3), 982-998. doi: 10.1111/j.1467-8624.2010.01534.x 
Quesada, A. A., Wiemers, U. S., Schoofs, D., \& Wolf, O. T. (2012). Psychosocial stress exposure impairs memory retrieval in children. Psychoneuroendocrinology, 37, 125-136. doi: 10.1016/j.psyneuen.2011.05.013

Quiroga, C. V., Janosz, M., Bisset, S. L., \& Morin, A. J. S. (2013). Early adolescent depression symptoms and school dropout: Mediating processes involving self-reported academic competence and achievement. Journal of Educational Psychology, 105(2), 552-560. doi: $10.1037 / \mathrm{a} 0031524$

Randolph, K. A., Fraser, M. W., \& Orthner, D. K. (2006). A strategy for assessing the impact of time-varying family risk factors on high school dropout. Journal of Family Issues, 27, 933-950. doi: 10.1177/0192513X06287168

Reynolds, A. J., Ou, S. R., \& Topitzes, J. W. (2004). Paths of effects of early childhood intervention on educational attainment and delinquency: A confirmatory analysis of the Chicago Child-Parent Centers. Child Development, 75, 1299-1328. doi: 10.1111/j.14678624.2004.00742.x

Reynolds, A. J., Temple, J. A., Robertson, D. L., \& Mann, E. A. (2001). Long-term effects of an early childhood intervention on educational achievement and juvenile arrest. JAMA: the journal of the American Medical Association, 285, 2339-2346. doi:

10.1001/jama.285.18.2339

Reynolds, J., Stewart, M., Macdonald, R., \& Sischo, L. (2006). Have adolescents become too ambitious? High school seniors' educational and occupational plans, 1976 to 2000. Social Problems, 53(2), 186-206. doi: 10.1525/sp.2006.53.2.186

Reynolds, J. R., \& Kirkpatrick Johnson, M. (2011). Change in the stratification of educational expectations and their realization. Social Forces, 90, 85-109. doi: 10.1111/j.14678624.2010.01563.x 
Roderick, M., Kelley-Kemple, T., Johnson, D. W., \& Beechum, N. O. (2014). Preventable failure: Improvements in long-term outcomes when high schools focused on the ninth grade year. Chicago, IL: University of Chicago Consortium on Chicago School Research (UChicago CCSR).

Romeo, R. D. (2013). The teenage brain: The stress response and the adolescent brain. Current Directions in Psychological Science, 22, 140-145. doi: 10.1177/0963721413475445

Roscigno, V. J., Tomaskovic-Devey, D., \& Crowley, M. (2006). Education and the inequalities of place. Social Forces, 84, 2121-2145.

Rumberger, R. W. (2011). Dropping out: Why students drop out of high school and what can be done about it. Cambridge, MA: Harvard University Press.

Rutter, M. (1996). Transitions and turning points in developmental psychopathology: As applied to the age span between childhood and mid-adulthood. International Journal of Behavioral Development, 19, 603-626. doi: 10.1177/016502549601900309

Sampson, R. J. (2012). Great American city: Chicago and the enduring neighborhood effect. Chicago: University of Chicago Press.

Sampson, R. J., \& Loeffler, C. (2010). Punishment's place: the local concentration of mass incarceration. Daedalus, 139(3), 20-31.

Sampson, R. J., Morenoff, J. D., \& Gannon-Rowley, T. (2002). Assessing "neighborhood effects": Social processes and new directions in research. Annual Review of Sociology, 28, 442-478. doi: 10.1146/annurev.soc.28.110601.141114

Schafft, K. A., \& Jackson, A. Y. (2010). Rural education for the twenty-first century: Identity, place, and community in a globalizing world. University Park, PA: Penn State Press. 
Schmader, T., Johns, M., \& Forbes, C. (2008). An integrated process model of stereotype threat effects on performance. Psychological Review, 115(2), 336-356. doi: 10.1037/0033295X.115.2.336

Schneider, B. L., \& McDonald, S.-K. (2007). Scale-up in education: Issues in practice (Vol. 2). Lanham, Maryland: Rowman \& Littlefield.

Schweinhart, L. J., Montie, J., Xiang, Z., Barnett, W. S., Belfield, C. R., \& Nores, M. (2005). Lifetime effects: the High/Scope Perry Preschool study through age 40. Ypsilanti, MI: High/Scope Press.

Semke, C. A., \& Sheridan, S. M. (2012). Family-school connections in rural educational settings: A systematic review of the empirical literature. School Community Journal, 22(1), 21-47.

Shanahan, M. J., Miech, R. A., \& Elder, G. H. (1998). Changing pathways to attainment in men's lives: Historical patterns of school, work, and social class. Social Forces, 77(1), 231-256.

Shonkoff, J. P., Garner, A. S., Siegel, B. S., Dobbins, M. I., Earls, M. F., McGuinn, L., .. . Wood, D. L. (2012). The lifelong effects of early childhood adversity and toxic stress. Pediatrics, 129, e232-e246.

Small, M. L. (2011). How to conduct a mixed methods study: Recent trends in a rapidly growing literature. Annual Review of Sociology, 37. doi: 10.1146/annurev.soc.012809.102657

Steele, C. M. (1997). A threat in the air: How stereotypes shape intellectual identity and performance. American Psychologist, 52(6), 613-629. doi: 10.1037/0003-066X.52.6.613

Steinberg, L. (2008). A social neuroscience perspective on adolescent risk-taking. Developmental Review, 28(1), 78-106. doi: 10.1016/j.dr.2007.08.002

Steinberg, L., \& Morris, A. S. (2001). Adolescent development. Annual Review of Psychology, 52, 83-110. doi: 10.1146/annurev.psych.52.1.83 
Strange, M., Johnson, J., Showalter, D., \& Klein, R. (2012). Why rural matters 2011-12: The condition of rural education in the 50 states. Washington, DC: Rural School and Community Trust.

Stroud, C. B., Davila, J., \& Moyer, A. (2008). The relationship between stress and depression in first onsets versus recurrences: A meta-analytic review. Journal of Abnormal Psychology, 117, 206. doi: 10.1037/0021-843X.117.1.206

Sum, A., Khatiwada, I., McLaughlin, J., \& Palma, S. (2011). No country for young men: deteriorating labor market prospects for low-skilled men in the United States. The Annals of the American Academy of Political and Social Science, 635(1), 24-55. doi: $10.1177 / 0002716210393694$

Taylor, P. J., Gooding, P., Wood, A. M., \& Tarrier, N. (2011). The role of defeat and entrapment in depression, anxiety, and suicide. Psychological Bulletin, 137(3), 391-420. doi: 10.1037/a0022935

Tierney, W. G. (1999). Models of minority college-going and retention: Cultural integrity versus cultural suicide. The Journal of Negro Education, 68(1), 80-91. doi: 10.2307/2668211

Tinto, V. (1975). Dropout from higher education: A theoretical synthesis of recent research. Review of Educational Research, 45(1), 89-125. doi: 10.3102/00346543045001089

Tinto, V. (1982). Limits of theory and practice in student attrition. The Journal of Higher Education, 53, 687-700. doi: 10.2307/1981525

Tinto, V. (1988). Stages of student departure: Reflections on the longitudinal character of student leaving. The Journal of Higher Education, 438-455.

Tinto, V. (1993). Leaving college: Rethinking the causes and cures of student attrition (2nd ed.). Chicago, IL: University of Chicago Press. 
Torche, F. (2010). Economic crisis and inequality of educational opportunity in Latin America. Sociology of Education, 83(2), 85-110. doi: 10.1177/0038040710367935

Turner, H. A., \& Schieman, S. (2008). Stress processes across the life course. Advances in Life Course Research, 13, 1-15. doi: 10.1016/S1040-2608(08)00001-4

van den Bos, E., de Rooij, M., Miers, A. C., Bokhorst, C. L., \& Westenberg, P. M. (2014). Adolescents' increasing stress response to social evaluation: Pubertal effects on cortisol and alpha-amylase during public speaking. Child Development, 85, 220-236. doi: 10.1111/cdev.12118

van Heesch, M. M. J., Bosma, H., Traag, T., \& Otten, F. (2012). Hospital admissions and school dropout: A retrospective cohort study of the 'selection hypothesis'. The European Journal of Public Health, 22, 550-555. doi: 10.1093/eurpub/ckr129

Venezia, A., \& Jaeger, L. (2013). Transitions from High School to College. The Future of Children, 23(1), 117-136.

Vinnerljung, B., Öman, M., \& Gunnarson, T. (2005). Educational attainments of former child welfare clients-a Swedish national cohort study. International Journal of Social Welfare, 14, 265-276. doi: 10.1111/j.1369-6866.2005.00369.x

Vitaro, F., Larocque, D., Janosz, M., \& Tremblay, R. E. (2001). Negative social experiences and dropping out of school. Educational Psychology, 21, 401-415. doi: $10.1080 / 01443410120090795$

Wehlage, G. G., Rutter, R. A., Smith, G. A., Lesko, N., \& Fernandez, R. R. (1989). Reducing the risk: Schools as communities of support. Philadelphia, PA: Falmer Press.

Weinfield, N. S., Bollmer, J., Krueger, H., \& Eaker, E. (2011). Recruitment and retention in longitudinal research on children and families: A quantitative and qualitative analysis. Paper presented at the National Children's Study Research Day, Bethesda, MD. 
Wickrama, K. A. S., O'Neal, C. W., \& Lorenz, F. O. (2013). Marital functioning from middle to later years: A life course-stress process framework. Journal of Family Theory \& Review, 5, 15-34. doi: 10.1111/jftr.12000

Willett, J. B., \& Singer, J. D. (1991). From whether to when: New methods for studying student dropout and teacher attrition. Review of educational research, 61, 407-450. doi: $10.3102 / 00346543061004407$

Wilson, S. J., Tanner-Smith, E. E., Lipsey, M. W., Steinka-Fry, K., \& Morrison, J. (2011). Dropout prevention and intervention programs: Effects on school completion and dropout among school-aged children and youth. Campbell Systematic Reviews, 8, 1-62.

Wilson, W. J. (1987). The truly disadvantaged: The inner city, the underclass, and public policy. Chicago: University of Chicago Press.

Wolke, D., Waylen, A., Samara, M., Steer, C., Goodman, R., Ford, T., \& Lamberts, K. (2009). Selective drop-out in longitudinal studies and non-biased prediction of behaviour disorders. The British Journal of Psychiatry, 195(3), 249-256. doi: 10.1192/bjp.bp.108.053751

Worrell, F. C. (1997). Predicting successful or non-successful at-risk status using demographic risk factors. The High School Journal, 81, 46-53.

Yair, G. (2009). Cinderellas and ugly ducklings: positive turning points in students' educational careers - exploratory evidence and a future agenda. British Educational Research Journal, 35, 351-370. doi: 10.1080/01411920802044388

Yang, Y., \& Land, K. C. (2008). Age-period-cohort analysis of repeated cross-section surveys: fixed or random effects? Sociological Methods \& Research, 36(3), 297-326. doi: $10.1177 / 0049124106292360$ 
Zell, E., \& Alicke, M. D. (2009). Contextual neglect, self-evaluation, and the frog-pond effect. Journal of Personality and Social Psychology, 97(3), 467-482. doi: 10.1037/a0015453 


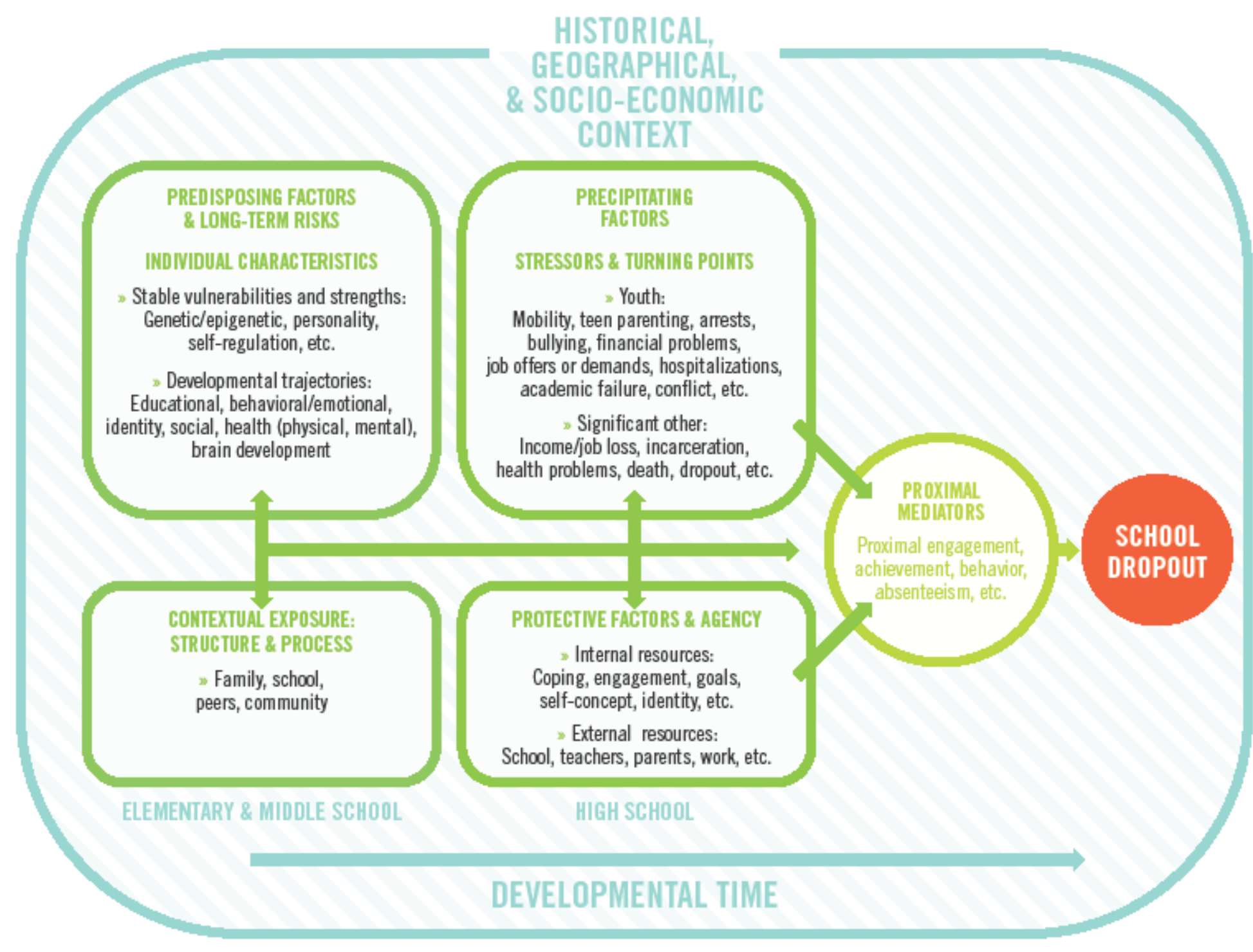

Figure 1. A stress process, life course model of high school dropout. 